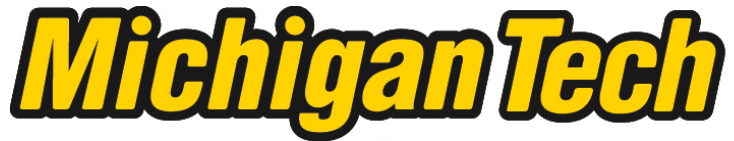 \\ Michigan Technological University Create the Future Digital Commons @ Michigan Tech
}

2013

\section{TanDEM-X High Resolution DEMs and Their Applications to Flow Modeling}

Kelly M. Wooten

Michigan Technological University

Follow this and additional works at: https://digitalcommons.mtu.edu/etds

Part of the Geographic Information Sciences Commons, Geology Commons, and the Remote Sensing Commons

Copyright 2013 Kelly M. Wooten

\section{Recommended Citation}

Wooten, Kelly M., "TanDEM-X High Resolution DEMs and Their Applications to Flow Modeling", Master's Thesis, Michigan Technological University, 2013.

https://doi.org/10.37099/mtu.dc.etds/645

Follow this and additional works at: https://digitalcommons.mtu.edu/etds

Part of the Geographic Information Sciences Commons, Geology Commons, and the Remote Sensing Commons 
TANDEM-X HIGH RESOLUTION DEMS AND THEIR APPLICATIONS TO FLOW MODELING

\author{
By
}

Kelly M. Wooten

\begin{abstract}
A THESIS
Submitted in partial fulfillment of the requirements for the degree of MASTER OF SCIENCE

In Geology
\end{abstract}

MICHIGAN TECHNOLOGICAL UNIVERSITY

2013

(C) 2013 Kelly M. Wooten 
This thesis has been approved in partial fulfillment of the requirements for the Degree of MASTER OF SCIENCE in Geology

Department of Geological/Mining Engineering \& Sciences

Thesis Advisor: $\quad$ Simon Carn

Committee Member: Andrew Harris

Committee Member: Ann Maclean

Department Chair: John Gierke, Interim Chair 


\section{Table of Contents}

Acknowledgements ........................................................................................ iv

Abstract...............................................................................................................v

1. Introduction....................................................................................................1

2. Study Site............................................................................................................2

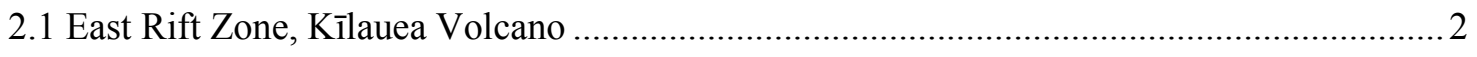

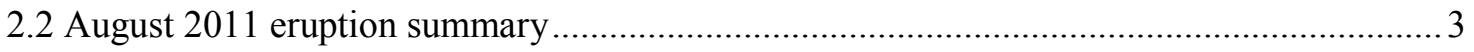

3. Data, Techniques and Methods .....................................................................6

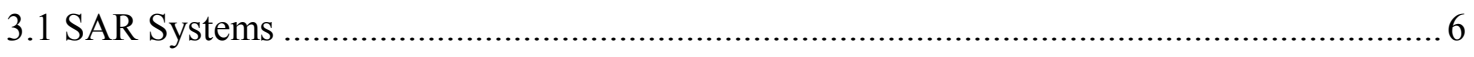

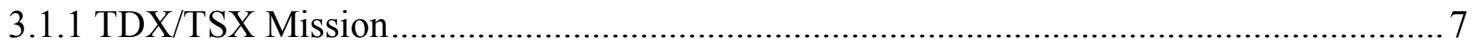

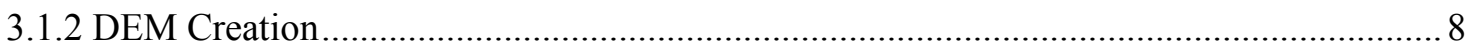

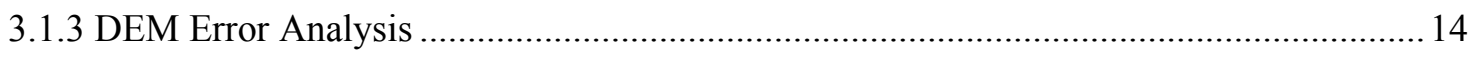

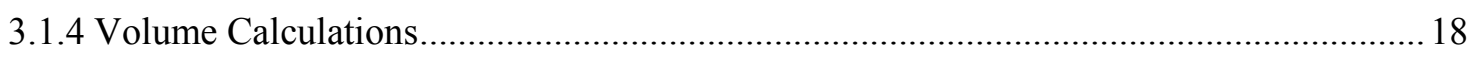

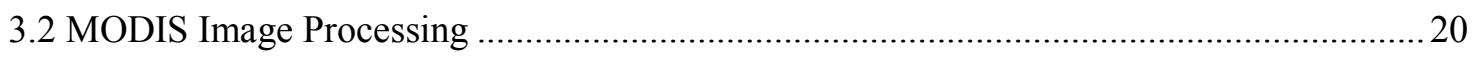

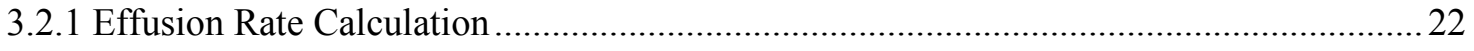

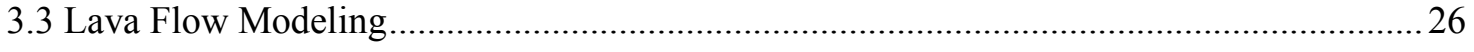

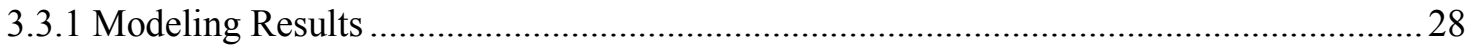

4. Discussion and Conclusions ...............................................................32

5. Future Work.................................................................................................34

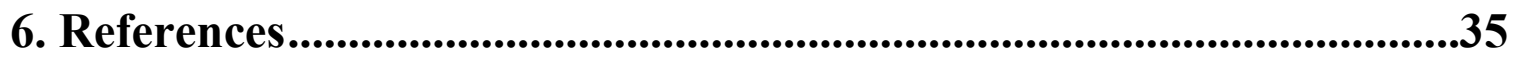

7. Appendices...............................................................................................................37 


\section{Acknowledgements}

I would like to thank my advisors, Simon Carn and Andy Harris, for the opportunity to work with you, and for the great opportunities afforded to me through the INVOGE program. I would like to thank the Hawaiian Volcano Observatory and staff for providing me with housing and office space during the data processing portion of this project. The entire staff deserves a thank you for many reasons, but a special mahalo goes out to Mike Poland for all of the support and guidance you have provided throughout the year. To Ann Maclean, thank you for sharing your expertise in GIS and image formatting. And to Rudiger Escobar Wolf, thank you for your patience and willingness to help with this project. I also want to thank Harold Garbeil from UH Manoa for assistance with the FLOWGO program. And finally, I would like to thank Intermap and the University of Hawai $i$ SOEST for permission to use the 2005 IfSAR DEM. 


\begin{abstract}
Lava flow modeling can be a powerful tool in hazard assessments; however, the ability to produce accurate models is usually limited by a lack of high resolution, up-to-date Digital Elevation Models (DEMs). This is especially obvious in places such as Kîlauea Volcano (Hawai i), where active lava flows frequently alter the terrain. In this study, we use a new technique to create high resolution DEMs on Kîlauea using synthetic aperture radar (SAR) data from the TanDEM-X (TDX) satellite. We convert raw TDX SAR data into a geocoded DEM using GAMMA software [Werner et al., 2000]. This process can be completed in several hours and permits creation of updated DEMs as soon as new TDX data are available. To test the DEMs, we use the Harris and Rowland [2001] FLOWGO lava flow model combined with the Favalli et al. [2005] DOWNFLOW model to simulate the 3-15 August 2011 eruption on Kîlauea's East Rift Zone. Results were compared with simulations using the older, lower resolution 2000 SRTM DEM of Hawai 1 . Effusion rates used in the model are derived from MODIS thermal infrared satellite imagery.

FLOWGO simulations using the TDX DEM produced a single flow line that matched the August 2011 flow almost perfectly, but could not recreate the entire flow field due to the relatively high DEM noise level. The issues with short model flow lengths can be resolved by filtering noise from the DEM. Model simulations using the outdated SRTM DEM produced a flow field that followed a different trajectory to that observed. Numerous lava flows have been emplaced at Kîlauea since the creation of the SRTM DEM, leading the model to project flow lines in areas that have since been covered by fresh lava flows. These results show that DEMs can quickly become outdated on active volcanoes, but our new technique offers the potential to produce accurate, updated DEMs for modeling lava flow hazards.
\end{abstract}




\section{Introduction}

A Digital Elevation Model (DEM) is arguably the most important piece of information used in models of geophysical mass flows. Whether modeling lava flows or lahars, a flow model uses a DEM to simulate the topography it will encounter. Model parameters can dictate the physical properties of the flow (e.g., yield strength and density), as well as environmental factors (e.g., air temperature and wind), but the flow trajectory is most dependent on the topography it is moving across. A summary diagram of the main features of lava flows and the various parameters used to model them can be found in Figure 3.10.

During the 1984 eruption of Mauna Loa volcano (Hawai $i$ ), an eruptive fissure along the northeast rift zone sent lava flows downslope, stalling less than $6 \mathrm{~km}$ (4 miles) from the town of Hilo. With the help of several natural diversion barriers, subsequent lava flows were diverted to sub-parallel flows, and the city of Hilo avoided a potential disaster. (U.S. Geological Survey http://hvo.wr.usgs.gov) This 'close call' brought lava flow hazards to the forefront of scientists', as well as most Hawai' $i$ residents' minds, and serves as an excellent example of the most important reason to maintain an up-to-date, high resolution DEM for accurate flow modeling and hazard assessments. Lava flow hazards are not only limited to Hawai i, but apply to any active basaltic volcano, including volcanoes such as Mt. Etna and Piton de la Fournaise.

In the case of Kîlauea Volcano (Hawai i i), the East Rift Zone has been hosting a longlived effusive eruption for 30 years, building a lava flow field that is constantly changing. During the span of this eruption, near-continuous outpouring of lava has altered the topography drastically, often on a daily basis. The occurrence of frequently changing topography is why it is important to model hazards such as lava flows with the most upto-date and accurate DEM possible.

The goals of this project are to demonstrate a new technique for accurate DEM generation, and test the resulting DEM as input to a lava flow model using a wellconstrained lava flow. In addition to a DEM, lava flow models also require estimates of the lava effusion rate as an input parameter. The study is divided into four main sections. Chapter 2 introduces our selected study site and provides a detailed account of the August 2011 eruption of Kîlauea Volcano. The next chapter presents a new technique to create timely, high resolution DEMs using TanDEM-X (TerraSAR-X Add-on for Digital Elevation Measurement) synthetic aperture radar (SAR) satellite data. The following section focuses on the procedure for estimating lava effusion rates from satellite data 
using Moderate resolution Imaging Spectroradiometer (MODIS) thermal infrared (TIR) imagery. The final section discusses the FLOWGO lava flow simulation model [Harris and Rowland, 2001], as well as the results of modeling the August 2011 eruption on one of the high-resolution TanDEM-X DEMs. For comparison, an older, lower resolution Shuttle Radar Topography Mission (SRTM; http://www2.jpl.nasa.gov/srtm/index.html) DEM was also used to model the August 2011 eruption. All models incorporated the eruption rate estimates derived from MODIS imagery, and the ground estimates from the Hawaiian Volcano Observatory (HVO).

\section{Study Site}

\subsection{East Rift Zone, Kīlauea Volcano}

Killauea Volcano is located on the southeastern side of Hawai' $i$ Island, abutted against the massive Mauna Loa volcano to the north and west. Kīlauea has been erupting along its East Rift Zone (ERZ), nearly continuously, since 1983. This is known as the $\mathrm{Pu}^{\prime} \mathrm{u}$ ' ${ }^{\circ}{ }^{‘} \bar{o}-$ Kupaianaha eruption, and continues as of this writing. During the past 30 years of activity, the eruption has undergone periods of lava fountaining and cone building, shield building, fissure eruptions, and long-term, continuous effusion. The eruption vent has shifted back-and-forth along the rift zone, but has predominately remained in the $\mathrm{Pu}$ ' $\mathrm{u}$ ' $\overline{\mathrm{O}}$ 'ō-Kupaianaha vicinity (Figure 2.1). During periods of prolonged effusion, lava flows often reach the coastline and flow into the ocean. Because of the reach of the flows, Kalapana, a town located approximately $15 \mathrm{~km}$ to the southeast of $\mathrm{Pu}^{\prime} \mathrm{u}{ }^{\prime} \mathrm{O}^{‘} \overline{\mathrm{o}}$, is frequently threatened by inundation. Much of the town was destroyed by lava flows in 1986 , and has continued to experience periodic lava flows that cover previous lava flows and bury newly built structures. The 21 July 2007 fissure eruption, which began on the eastern flank of $\mathrm{Pu}^{\prime} \mathrm{u}$ ' $\overline{\mathrm{O}}^{‘} \overline{\mathrm{o}}$, also caused concern to communities in Pāhoa and the surrounding areas along the eastern tip of the island. Fortunately, the channel fed flows did not tube over and stalled before they posed a hazard to the communities downslope. [Kauahikaua, 2007]

The flow field, as of December 2012, covers an area of $125.5 \mathrm{~km}^{2}\left(48.4 \mathrm{mi}^{2}\right)$, and has added 202 hectares (500 acres) of new land to the southeast shore (U.S. Geological Survey http://hvo.wr.usgs.gov). In this study, we focus on an eruption that occurred on the western flank of $\mathrm{Pu}^{\prime} \mathrm{u}^{\prime} \overline{\mathrm{O}}^{‘} \mathrm{o}$ in August 2011, which was particularly well characterized in the field by HVO. 


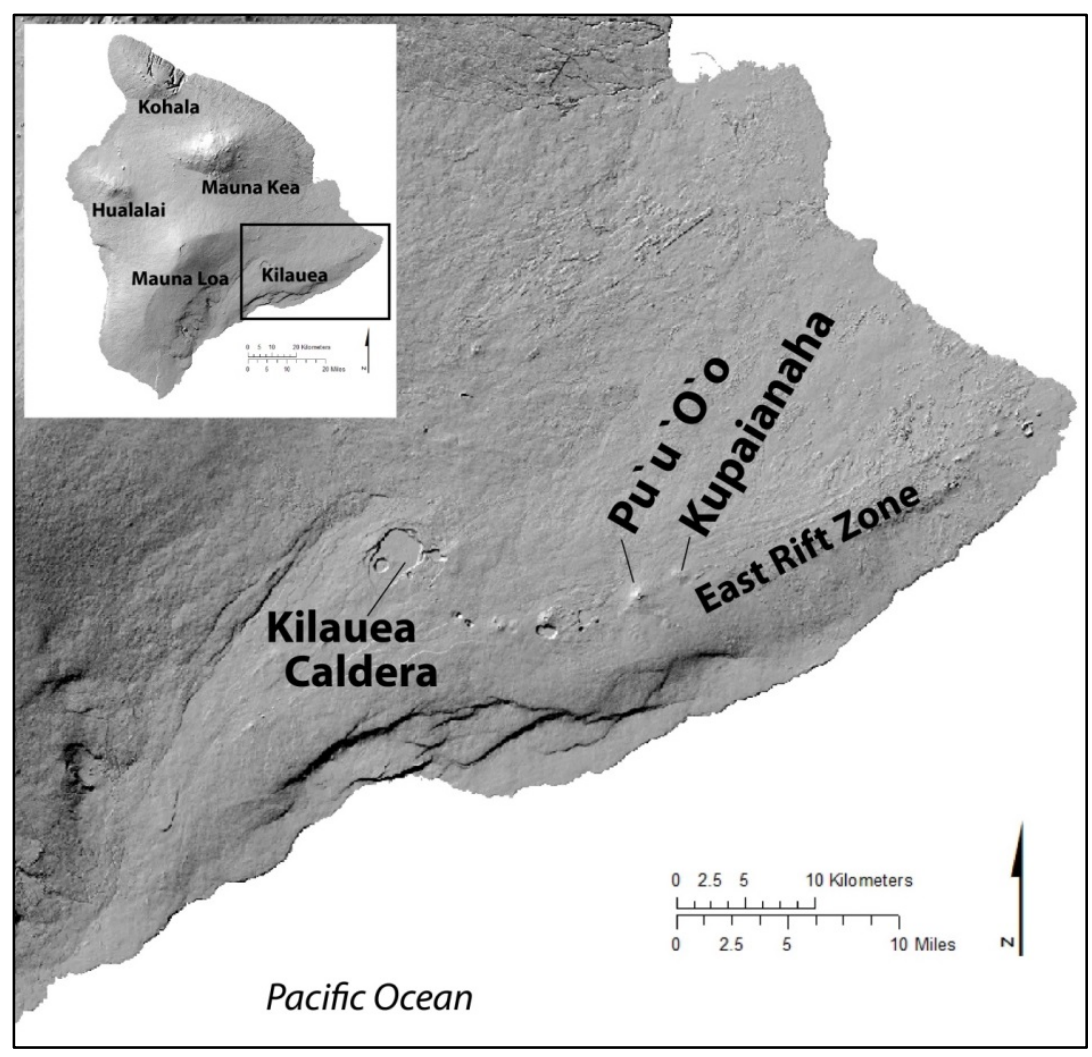

Figure 2.1 Location map of Kîlauea Volcano. Inset: Hawai ${ }^{i}$ Island — the most southeastern island in the Hawaiian Island chain.

\subsection{August 2011 eruption summary}

The August 2011 eruption was a short-lived event which initiated the collapse of the crater at $\mathrm{Pu}^{\prime} \mathrm{u}$ ' $\overline{\mathrm{O}}^{‘} \overline{\mathrm{o}}$, a pyroclastic cone on the ERZ of Kîlauea Volcano. Below is the summary of the 12 day eruption, as well as the events that led to its inception (T. Orr and M. Patrick, unpublished data, 2011).

For several months leading up to the eruption, a perched lava lake occupied the eastern portion of $\mathrm{Pu}^{\prime} \mathrm{u}$ ' $\mathrm{O}^{‘} \overline{\mathrm{o}}$ 's crater. The lava level in the lake rose during this period, episodically overflowing the rim and filling the crater slowly. In late June 2011, overflows from the lake largely stopped as the crater floor began to lift in a piston-like fashion. The uplift was accommodated by a circumferential fracture at the interface between the crater floor and the crater wall. Lava erupting from the fracture flooded the outer edges of the crater, forming a mote around the crater's bulging center. By late July, the central part of the crater floor, still occupied by a lava lake, was higher than the crater's eastern and western rims. Lava, erupting from the circumferential fracture, eventually overflowed the southwestern edge of the crater, producing a short-lived flow that traveled about $1 \mathrm{~km}$ before stalling. 
On August 3, $\mathrm{Pu} u^{\prime} \mathrm{u}$ ' $\overline{\mathrm{O}}^{‘} \overline{\mathrm{o}}$ 's crater floor began to collapse, and the western rim and flank of the cone was forced up, as magma suddenly intruded beneath the cone's western flank. At 14:18 H.S.T. (Hawaiian-Aleutian Standard Time), lava broke the surface along a series of four fissures low on $\mathrm{Pu}^{\prime} \mathrm{u}$ ' $\overline{\mathrm{O}}^{‘} \overline{\mathrm{o}}$ 's western flank. The flood of lava that ensued split into two branches - a broad northwest branch that advanced into native forest, and a narrower southern branch that followed the western edge of the older $\mathrm{Pu}^{\prime} \mathrm{u}$ ' $\overline{\mathrm{O}}^{`} \bar{o}$ flow field. Within three hours, as the magma body beneath $\mathrm{Pu}^{`} \mathrm{u}{ }^{`} \overline{\mathrm{O}}^{`} \overline{\mathrm{o}}$ drained, the crater floor had dropped about $80 \mathrm{~m}$ and the southern flow had advanced about $4 \mathrm{~km}$. Over the first three hours, the estimated time-averaged effusion rate was $111-333 \mathrm{~m}^{3} \mathrm{~s}^{-1}$.

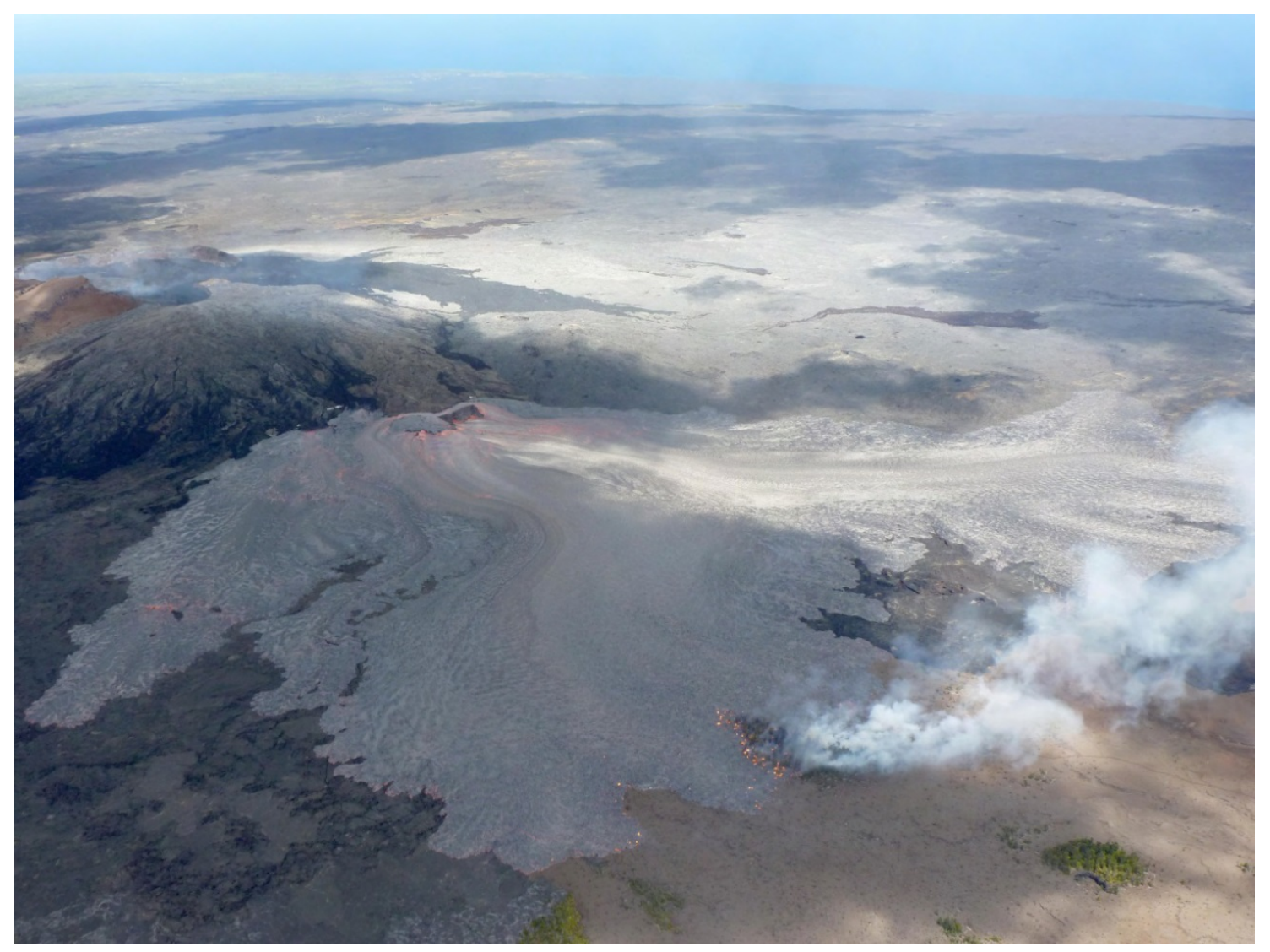

Figure 2.2 Image taken from a tourist helicopter on 3 August 2011, approximately 14 minutes after the onset of the eruption. The image was taken looking southeast with $\mathrm{Pu}^{\prime} \mathrm{u}{ }^{\prime} \overline{\mathrm{O}}^{‘} \bar{o}$ cone in the left margin. Image courtesy of the USGS Hawaiian Volcano Observatory. See Appendix D for documentation of permission to republish this material.

After the initial outpouring of lava, effusion rates slowed. The two flow branches stalled, and lava began to accumulate at the western base of the $\mathrm{Pu}^{\prime} \mathrm{u}{ }^{\prime} \overline{\mathrm{O}}^{‘} \overline{\mathrm{o}}$ cone, constructing a perched lava pond. A low shield grew over the vent area. Repeated levee failures from the lower edges of the perched pond buried much of the early-emplaced lava beneath 
rubbly levee material and 'a'ā flows, which barely extended beyond the initial flow margin in a few places. The eruption continued to wane over the following days and ended on August 15.

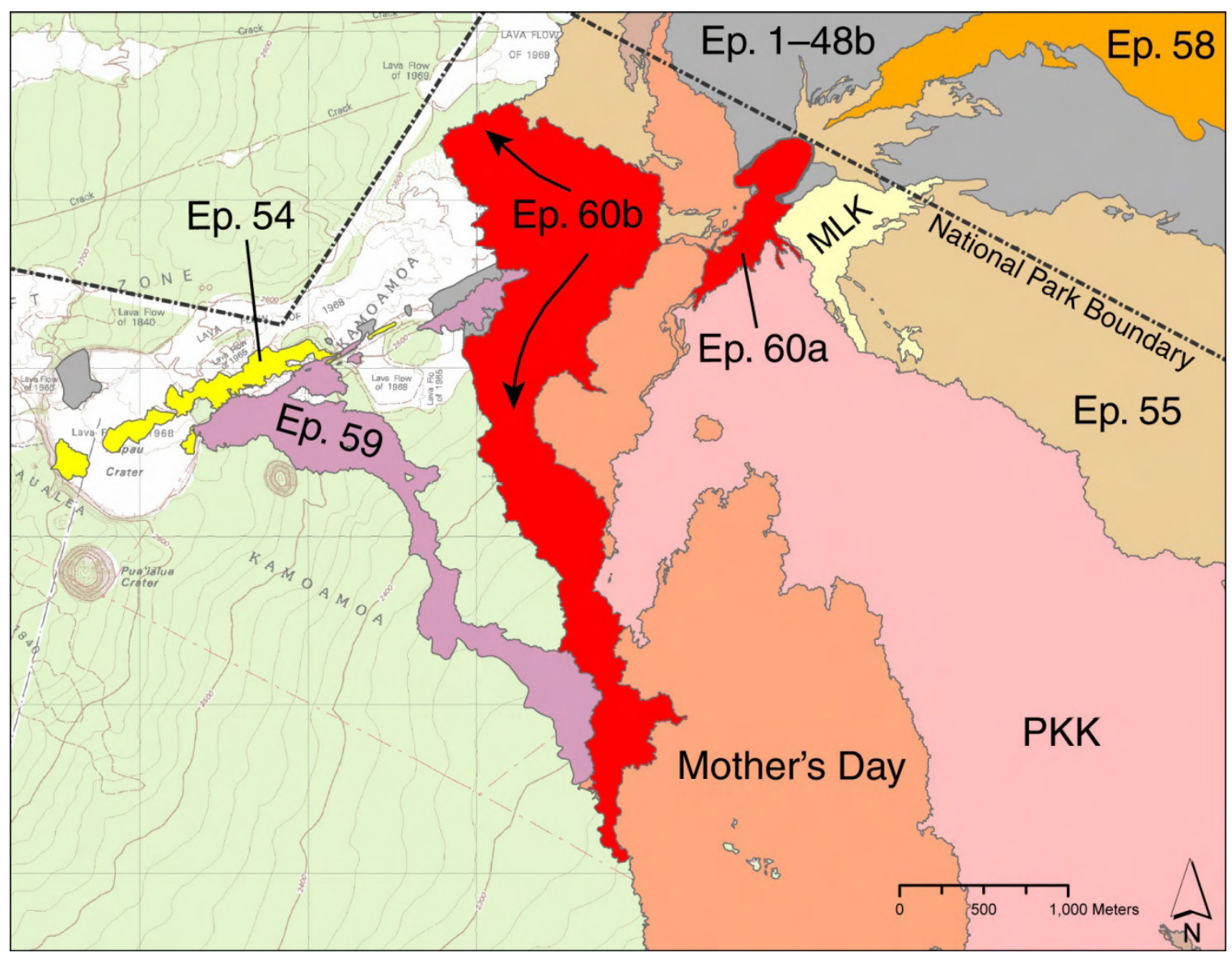

Figure 2.3 Map of numerous eruptive episodes during the ongoing $\mathrm{Pu}^{`} \mathrm{u}$ ' ${ }^{`}{ }^{`} \bar{o}-\mathrm{Kupaianaha}$ eruption. Episode $60 \mathrm{~b}$, colored in red, is the flow modeled in this study. Map courtesy of the USGS Hawaiian Volcano Observatory. See Appendix D for documentation of permission to republish this material.

We selected this particular eruption for our study for several reasons. The flow did not reach the ocean, so the entire volume could be constrained. It was also in an area accessible to HVO geologists, providing them quick access for mapping and observations. Figure 2.3 is a map of several eruptive episodes in the current eruption, including the August 2011 flow (Episode 60b). The flow was mapped with a handheld GPS, so the flow extent is known to the accuracy of the GPS ( \pm 15 meters). The flow was also short-lived and occurred between TanDEM-X data acquisitions, allowing us to study topographic changes between successive DEMs. 
The following sections will discuss the background and methodology used to create DEMs from a satellite radar system, derive effusion rates from satellite data, and, in turn, use this information to model the August 2011 eruption.

\section{Data, Techniques and Methods}

\subsection{SAR Systems}

A SAR system is one of a number of air- and space-borne sensors that can be used to generate a DEM. The system is generally mounted on a satellite (although some airborne systems are in use) and operates in the microwave portion of the electromagnetic spectrum, enabling the radar waves to "see" through the atmosphere and clouds. The latter property of microwave radiation is one of the key advantages of the use of SAR in volcanic regions, which are frequently cloud-covered. SAR records data both day and night because it is an "active" imaging system, which means it generates a pulse of radiation and measures the return, rather than passively recording naturally emitted or reflected radiation. The radar antenna points toward the Earth at an inclination of $20-50$ degrees with respect to nadir (the point directly beneath the satellite on the Earth's surface). In a plane perpendicular to the satellite's orbit, the antenna sends out radar pulses that are scattered by objects on the Earth's surface. Some of this radiation is reflected back and measured by the satellite. The area on the ground illuminated by the radar is the antenna footprint, which traces a specific swath width along the Earth's surface. As the satellite orbits the Earth, it collects images along strips. This is known as 'Stripmap' mode and is used by the TanDEM-X mission (see below) to acquire data.

A raw SAR image contains pixels that are sized according to the spatial resolution of the radar system. Each pixel in a SAR image contains two pieces of information stored as a complex number: amplitude and phase. The amplitude of the signal returned to the sensor largely depends on the roughness of the surface being imaged. Highly reflective surfaces (at microwave wavelengths), such as water, have low amplitudes because only a small portion of the signal is reflected back to the sensor. On the other hand, areas with high surface roughness, such as an 'a'à lava flow or an urban area, scatter a large fraction of the signal back to the sensor, producing a high amplitude. In contrast, the phase contains information about the distance between the satellite and the ground. Although the absolute number of wavelengths between the surface and the satellite is unknown, the last fraction of the wavelength, known as the phase, can be measured. [Ferretti et al., 2007]

In a typical single-pass SAR system, two SAR images of the same area, acquired from the same point in space, but at different times, are 'interfered' to create an interferogram. An interferogram is simply the difference between the phase values for two image 
acquisitions, once the images have been aligned based on their amplitudes. These phase changes correspond to topography, as well as changes in the distance between the satellite and the ground along the radar's line-of-sight (slant range; which is a mix of vertical and horizontal change) over the time between the image acquisitions. Within the interferogram are areas of coherence and incoherence. An image is incoherent when there has been too much change in the ground surface between acquisitions. Areas that show incoherence have changed somehow with respect to the way they are viewed, so over time, incoherence occurs because trees blow in the wind, lava flows cover older surfaces, etc. If the images are obtained simultaneously, such as the TDX data (explained below), the interferograms are generally coherent, since there is no time difference between acquisitions. The few incoherent areas in these interferograms are caused by the slightly different viewing geometries of the steep crater walls or fault scarps.

If the satellite is not in exactly the same point in space during the two image acquisitions, the interferogram will contain phase differences due to topography, as well as deformation of the Earth's surface. If deformation is of interest, the topography must be removed by incorporating an existing DEM into the interferometric processing. If, however, the goal of the study is to map topography, a DEM can be generated directly from the interferogram. In this study, our data are acquired from the TanDEM-X mission, a radar system that utilizes a pair of satellites that simultaneously image the same point on the Earth's surface from slightly different locations in space. A DEM can be created from these data, which contain no signal from deformation of the surface (since the images are acquired at the same time). The step-by-step process of creating a DEM from these data is outlined below in the DEM Creation section (section 3.1.2).

Prior to the TanDEM-X mission, the Shuttle Radar Topography Mission (SRTM), flown on Space Shuttle Endeavour in February 2000, created a DEM of approximately 80 percent of the Earth's surface (between about $60^{\circ}$ north and $56^{\circ}$ south latitude). This mission used two SAR systems as well, but the two radar antennas were on the same shuttle. The complete SRTM DEM was created using C-band radar (5.6 cm wavelength) and produced a DEM with $30 \mathrm{~m}$ spatial resolution, while an X-band radar $(3.1 \mathrm{~cm}$ wavelength) was used for experimental purposes (i.e. TanDEM-X prototype). [Farr et al., 2007]

\subsubsection{TDX/TSX Mission}

TanDEM-X (hereafter, TDX) and TerraSAR-X (TSX) are two near-identical radar satellites that are currently orbiting the Earth in a tandem formation. Launched in June 2010, TDX joined the pre-existing TSX satellite (in orbit since 2008) to begin a mission aimed at creating a high-precision global DEM according to the specifications of the HRTI-3 (High Resolution Terrain Information) standards. The standards require a 2- 
meter relative vertical accuracy on flat ground $(<20 \%)$ with an absolute vertical accuracy of 10 meters, and a spatial resolution of 12 meters [Krieger et al., 2007]. This mission is a public-private partnership between the German Space Agency (DLR) and EADS Astrium GmbH (European Aeronautic Defense and Space company) [During et al., 2008].

Each satellite is instrumented with an advanced high-resolution X-band SAR. The Xband has a frequency range of $8-12 \mathrm{GHz}$ and spans the $2.5-4 \mathrm{~cm}$ wavelength of the electromagnetic spectrum. The projected lifetime for TDX is 5.5 years, overlapping with TSX by 3 years [Krieger et al., 2007].

Data acquisition can be performed in 4 modes: pursuit monostatic, bistatic, alternating bistatic, and simultaneous transmit. Beginning in October 2010, TDX and TSX began acquiring in bistatic mode, where one satellite transmits to the Earth's surface, and both satellites record the return signal simultaneously. For the creation of DEMs, the bistatic mode is ideal because, with the simultaneous acquisitions, there are no errors due to decorrelation or atmospheric changes over time. TDX and TSX follow a sunsynchronous, dusk-dawn orbit. More specifically, they fly in a helix-like pattern along their respective orbits, approximately $250-500$ meters from one another. [Krieger et al., 2007]
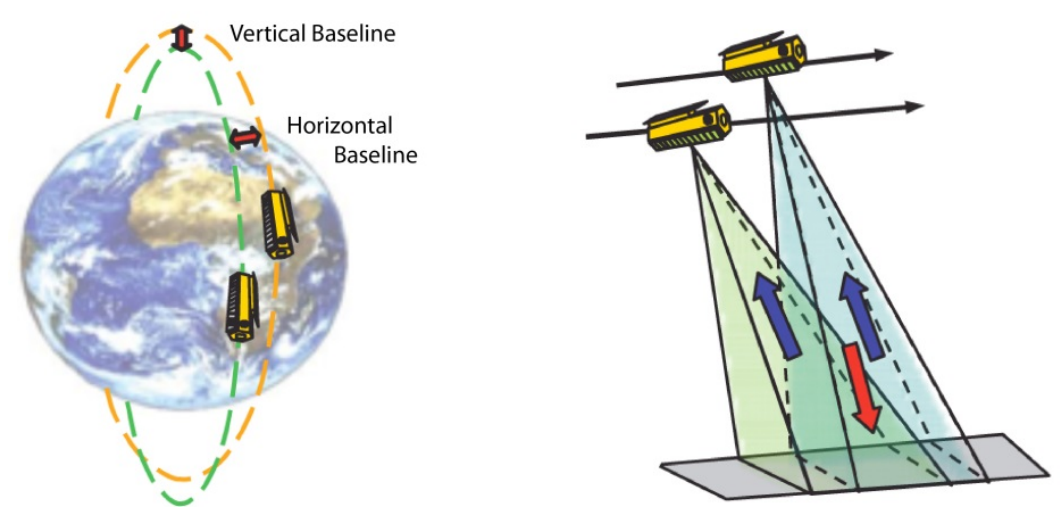

Figure 3.1 Left: Orbital arrangement of the TDX and TSX satellites flying in formation. Right: Bistatic data acquisition mode. Figures taken from Krieger et al. [2005]. See Appendix D for documentation of permission to republish this material.

\subsubsection{DEM Creation}

All available raw data from TDX and TSX were ordered for Kīlauea, resulting in 39 image pairs spanning from 30 June 2011 to 17 November 2012. The data were acquired through a proposal to the DLR by Dr. Michael Poland, a geophysicist at HVO. He received a grant from the agency, so the data were free. The TDX data are available 
worldwide, but there are only a few places where repeated data collections are made. Hawai $i$ is one of those places because of the DLR grant, as well as that fact that Hawai $i$ is universally recognized as an interesting place to study.

The data come in two different tracks, each containing a summit and flow field pass (see Figure 3.2). Track 24 data are acquired at 6:00 H.S.T, while track 32 scenes are acquired at approximately 18:00 H.S.T.

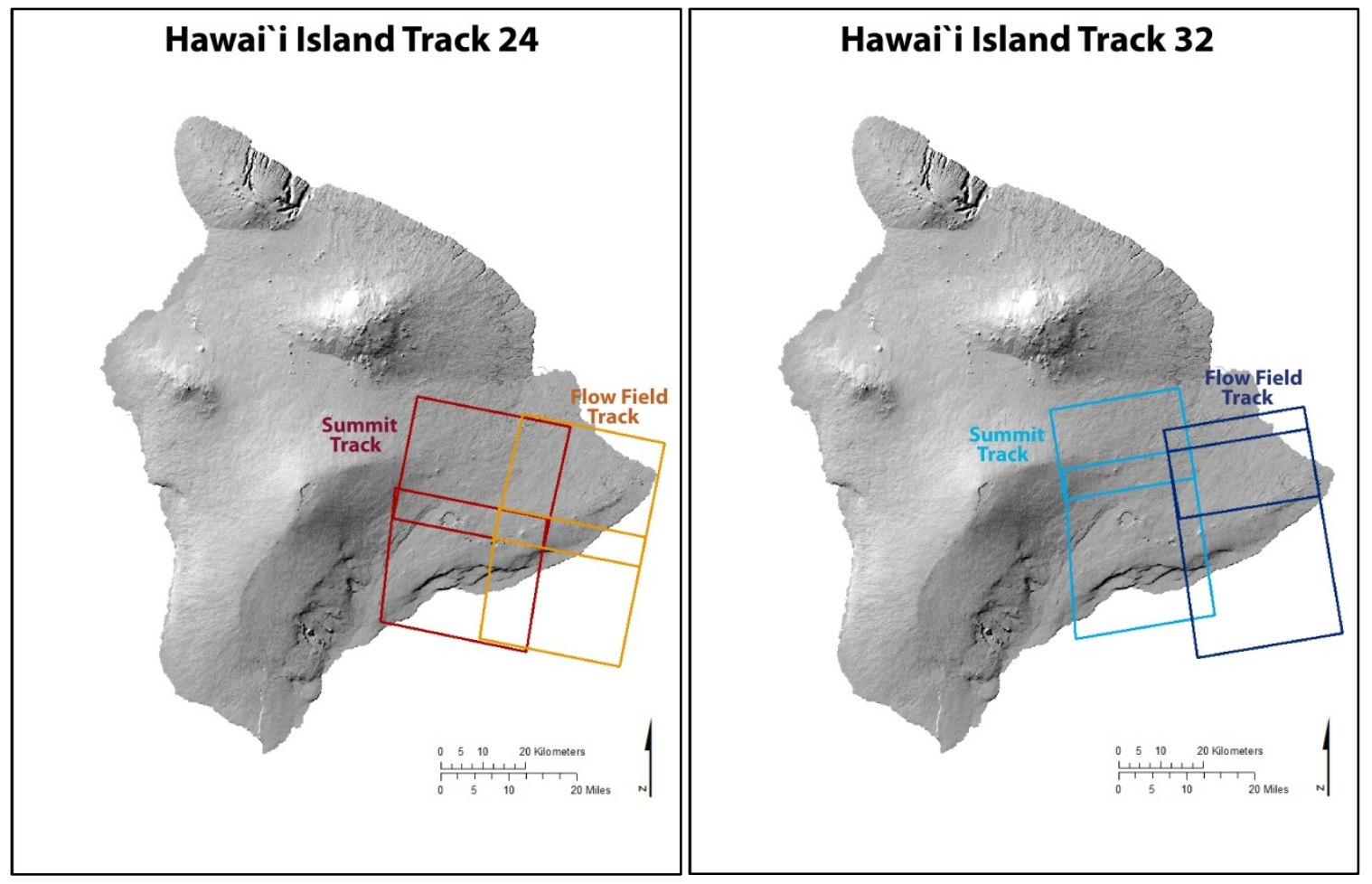

Figure 3.2 TanDEM-X track 24 and 32. Each track contains two TDX and two TSX images for both the summit and flow field. The two images (color coordinated here) are stitched together to create a single TDX and TSX image for the summit and the flow field, respectively.

There are two types of error in TDX data that impact DEM formation. The first is atmospheric error, especially during the track 32 evening passes when heavy cloud cover is more likely. Even though radar can see through clouds, the signal is still affected. While temporal decorrelation in the TDX interferograms is not a problem (because there is no gap in time between scene acquisitions), it is important to note that there will be differences in atmospheric conditions between successive DEMs. Comparing DEMs may therefore result in some atmospheric artifacts. The second error is due to the orbital baseline, which is the distance between satellites at the time of image acquisition. This error becomes significant when the two satellites are not exactly aligned (which turns out to be most of the time). This correction is explained in more detail in steps 6 and 7 below. 


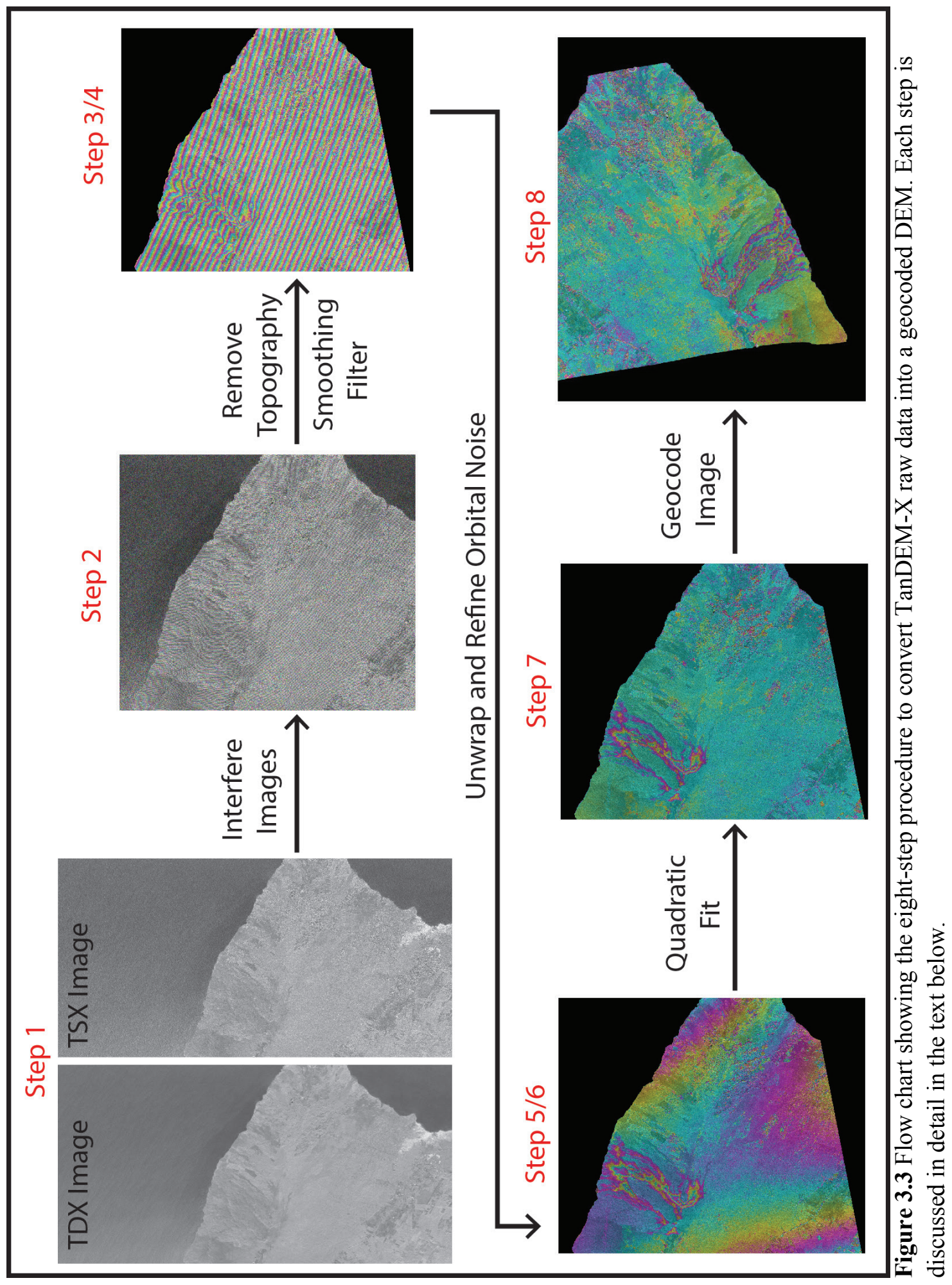


The following steps outline a procedure to convert TanDEM-X raw data into a geocoded DEM. Each step was run using the GAMMA software [Werner et al., 2000].

\section{Step 1: SLC Creation}

We begin by creating four single look complex (SLC) scenes from data acquired on the same date - two from TDX and two from TSX. The two scenes from each satellite cover different parts of Kîlauea (summit and flow field) along the same orbital track and overlap in time by one to two seconds. To create a single scene for each satellite, we calculate the offset needed to align and overlay them. Once the offset is known, we combine the images to create a single SLC each for TDX and TSX that spans the entire acquisition time over our area of interest.

Step 2: Interfere the Images

To produce an interferogram, we must calculate the offset between the two SLCs (one from TDX and one from TSX) when they are overlain. Once they are correctly aligned, we interfere their phase values to produce an interferogram. The phase difference between the two SLCs that is represented by the interferogram contains contributions due to topography, noise, atmosphere, and orbital error. Orbital parameters calculated from the interferogram are stored in a "baseline" file (with "baseline" referring to the distance between the two satellites at the time of data acquisition) for later use.

\section{Step 3: Remove Topography}

To remove the topographic contribution to the phase values in the interferogram, we use NOAA's 2005 IfSAR DEM, which has 4.5 meter resolution over the Island of Hawai' $i$. The GAMMA software simulates how the DEM would look to the TSX-TDX pair and then subtracts those phase values from the interferogram. The resulting differential interferogram contains phase due to the difference in topography that exists between the time of TSX-TDX image acquisition and the 2005 IfSAR DEM, as well as other error sources (primarily atmospheric artifacts and orbital uncertainty). The purpose of this step is to reduce the interferogram to topography that is new since 2005, which allows for easy viewing of topographic change over time.

\section{Step 4: Smoothing}

Because the data are noisy and contain areas of incoherence (where the radar signal is weak, such as steep crater walls), we implement an adaptive filtering algorithm to smooth 
the data and reduce phase noise [Goldstein and Werner, 1998]. This helps to reduce some of the variability and incoherence in the data.

Step 5: Unwrap Image

An interferogram contains phase values that vary between 0 and 2 pi. These values must be converted, or unwrapped, into a continuous set of phase data that represent changes in the slant range distance between the satellite and the ground. Unfortunately, the fullresolution interferogram is too large in size to unwrap without errors. The limitation is that there are too many bytes of data to unwrap the full image, so it must be broken into subsets before it can be unwrapped. Using simple averaging, we downsample the topography-corrected interferogram (and accompanying coherence map) image by a factor of four. We then create a mask based on the coherence map that will only unwrap data that have a certain level of coherence (so incoherent areas, like crater walls and fault scarps, will not be included in the unwrapping). The downsampled image is unwrapped and then oversampled (using simple interpolation) to return it to its original size. Finally, the unwrapped image is used as a guide, or model, for unwrapping the original differential interferogram.

\section{Step 6: Refine Orbital Error}

Even at this stage of data processing, many differential interferograms still contain significant noise due to imprecise orbital correction. We refined the orbital parameters by comparing the elevations of a set of ground control points sampled from the IfSAR DEM to points in the topographic interferogram (i.e., the interferogram created in Step 2). The difference between the predicted (from the DEM) and observed (from the Step 2 interferogram) elevations provides a correction that can be added to the orbital information stored in the baseline file. This refines our knowledge of the satellites' orbits and positions relative to one another, and is applied to the unwrapped, topographysubtracted image from Step 5.

\section{Step 7: Quadratic Fit}

Even with the refinements to the orbital information described above, residual phase differences due to imprecise orbits often still exist in the data. As a final procedure to remove any remaining orbital phase, a quadratic function is fit to the residual phase and subtracted from the unwrapped interferogram. The resulting image, which has been corrected for orbital errors and had the 2005 IfSAR topography subtracted, contains mostly topography that has changed with respect to the 2005 DEM. It also contains instrumental noise, which gives the image a granular appearance. 


\section{Step 8: Create a Geocoded Height Map}

Up to this point, the topography in the interferograms has been processed in terms of radar phase (which is a function of the radar wavelength), rather than elevation in meters. With knowledge of the orbital baseline and radar wavelength, these phase values can be converted to meters. The image is then geocoded (in other words, converted from radar coordinates to ground-based coordinates), producing a georeferenced map of the vertical elevation difference between the 2005 DEM and the time of image acquisition. We refer to this as a Digital Elevation Difference Model (DEDM). The data can be combined with the 2005 DEM to create an updated DEM or used to identify topographic change over time (e.g., to assess the volume of a lava flow erupted after the 2005 DEM was acquired).

Following the steps outlined above, 34 of the 39 available image pairs were successfully processed into georeferenced DEDMs. The spatial resolution for the raw TDX data is 3 meters, but the resolution of the final DEDM is 4.5 meters (consistent with the IfSAR DEM resolution). This is still well below the HRTI-3 standard of 12 meters. The HRTI-3 standards also call for an absolute vertical accuracy of 10 meters, but the vertical accuracy in our DEDMs are variable, and range from 3-10 meters (in track 32; see Table $3.1)$. 


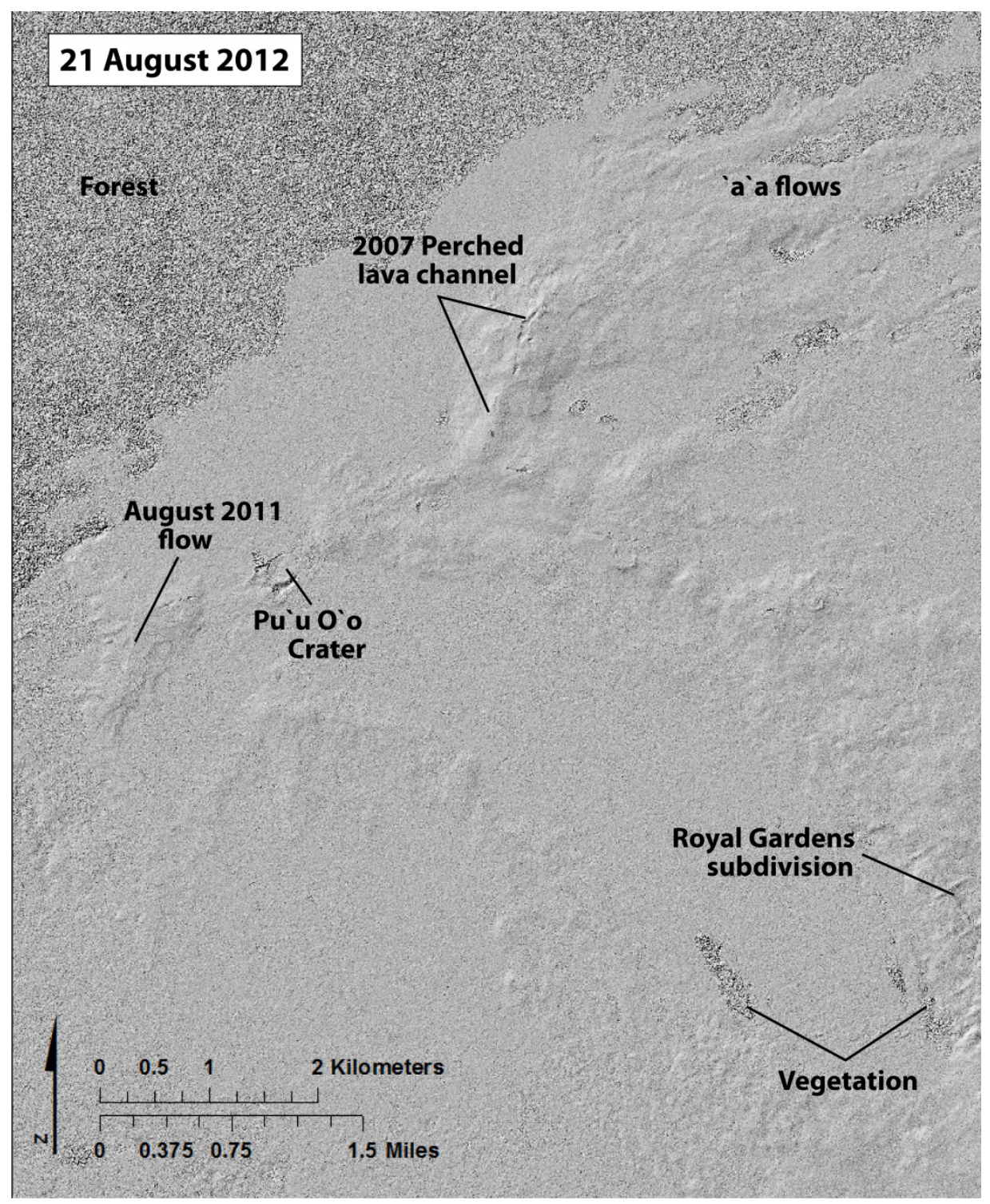

Figure 3.4 A hillshade image of the $\mathrm{Pu}^{`} \mathrm{u}$ ' $\mathrm{O}^{`} \overline{\mathrm{o}}-\mathrm{Kupaianaha}$ flow field on the 21 August 2012 difference DEM. Several features are labeled to highlight the quality and resolution of the DEDM.

\subsubsection{DEM Error Analysis}

All of the TanDEM-X DEDMs have a granular or speckly appearance to varying degrees, which can be attributed to noise in the radar instrument, as well as to how the radar beam interacts with the ground surface. The speckle pattern is caused by random phase signals (created by many small scatterers of a comparable size to the radar wavelength) that have undergone multiple reflections before combining with the directly reflected radiation. This causes the phase measurement to not reflect the true range between the satellite and 
ground surface and makes the SAR resolution cell (i.e., pixel) appear closer to, or farther away from, the sensor than in reality. [Ferretti et al., 2007]
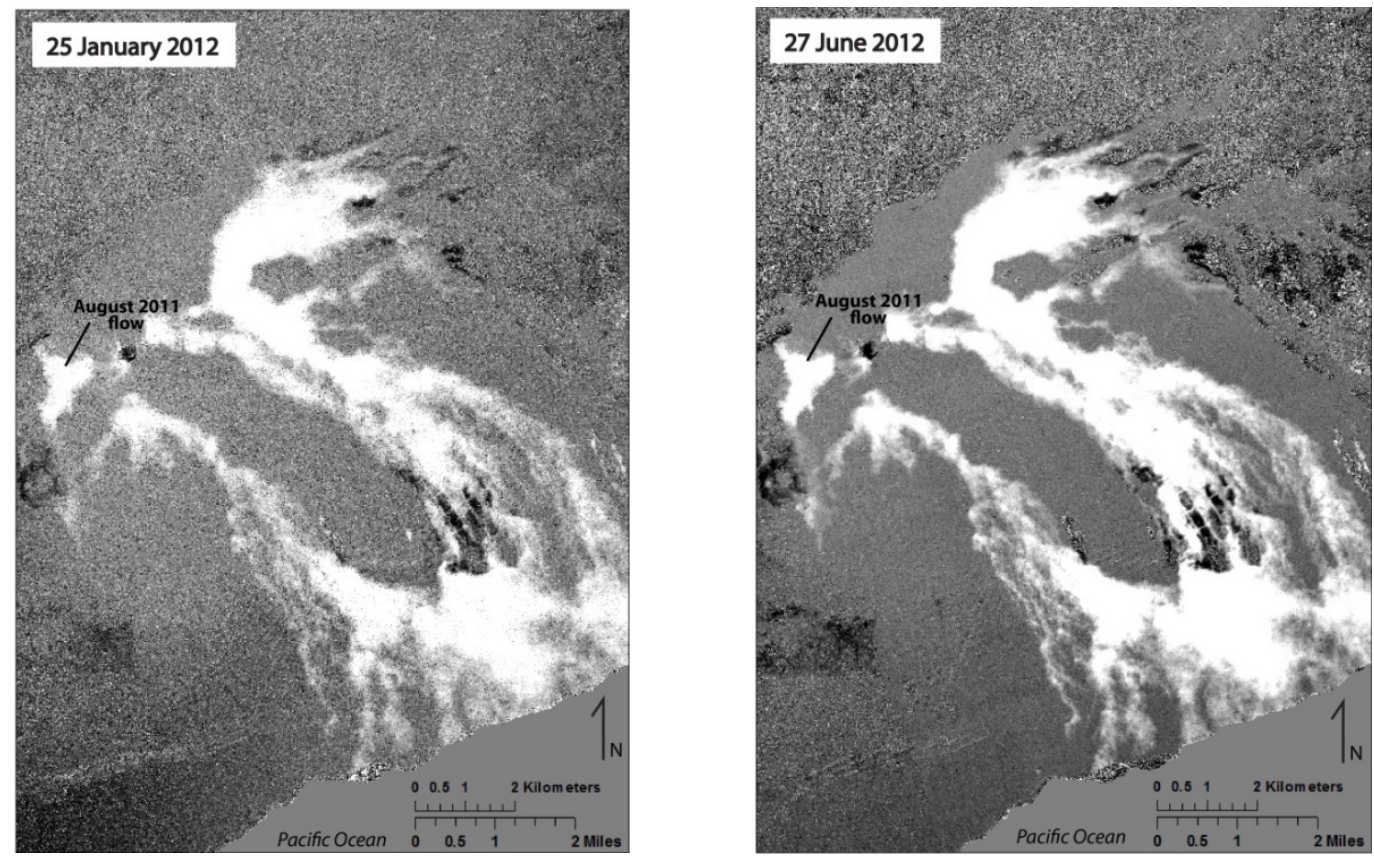

Figure 3.5 An example of two DEDMs created from the TDX data, showing differences in topography between the 2005 IfSAR DEM and the dates indicated. Note the difference in appearance between the two acquisitions due to noise.

Figure 3.5 presents two of the TDX DEDMs side-by-side to compare the noise levels in each. Since topography from 2005 has already been removed, what remains is the topographic change that occurred between 2005 and 2012. The bright white areas represent the largest change and can be attributed to emplacement of lava flows. The forested area at the top of each image is incoherent, creating a salt-and-pepper appearance in the image, while the less-speckled areas in the image centers (especially apparent in the 27 June 2012 image), surrounding the white areas that denote new flows, are unvegetated surfaces representing older lava flows.

To examine the noise more thoroughly, two areas on the flow field were chosen for statistical analysis on 13 DEDMs from the track 32 flow field pass. These areas were specifically targeted because they represent regions that are known to have not changed since at least 2005 (i.e., no new lava flows covered these areas between the acquisition of the 2005 IfSAR DEM and the 2012 TDX DEDM). Using the ENVI 4.8 software, two rectangular regions of interest (ROIs) were drawn on the DEDMs in these areas (see Figure 3.6). Histograms of each ROI (both of which contain approximately 45,000 points) were created, and the mean and standard deviation were recorded in Table 3.1. A 
linear interpolation was also performed on the cumulative probability curve of each ROI to calculate the value that crosses the 5 and 95 percent quantiles. These numbers give the range of values that 90 percent of the data will fall between. In a perfect (noise-free)

DEDM these areas should show zero elevation difference, but since they are not (due to phase noise), we use this range to assign a vertical error to each DEDM. As noted in table 3.1, each DEDM will have a different error. For example, in the 25 January 2012 DEDM in Figure 3.5, 90\% of the pixel values across both ROIs fall between -5.4 and +6.6 meters, but in the 27 June 2012 DEDM, which has a noticeably smoother appearance, the $90 \%$ confidence interval spans a much smaller range of -2.4 to +1.7 meters.

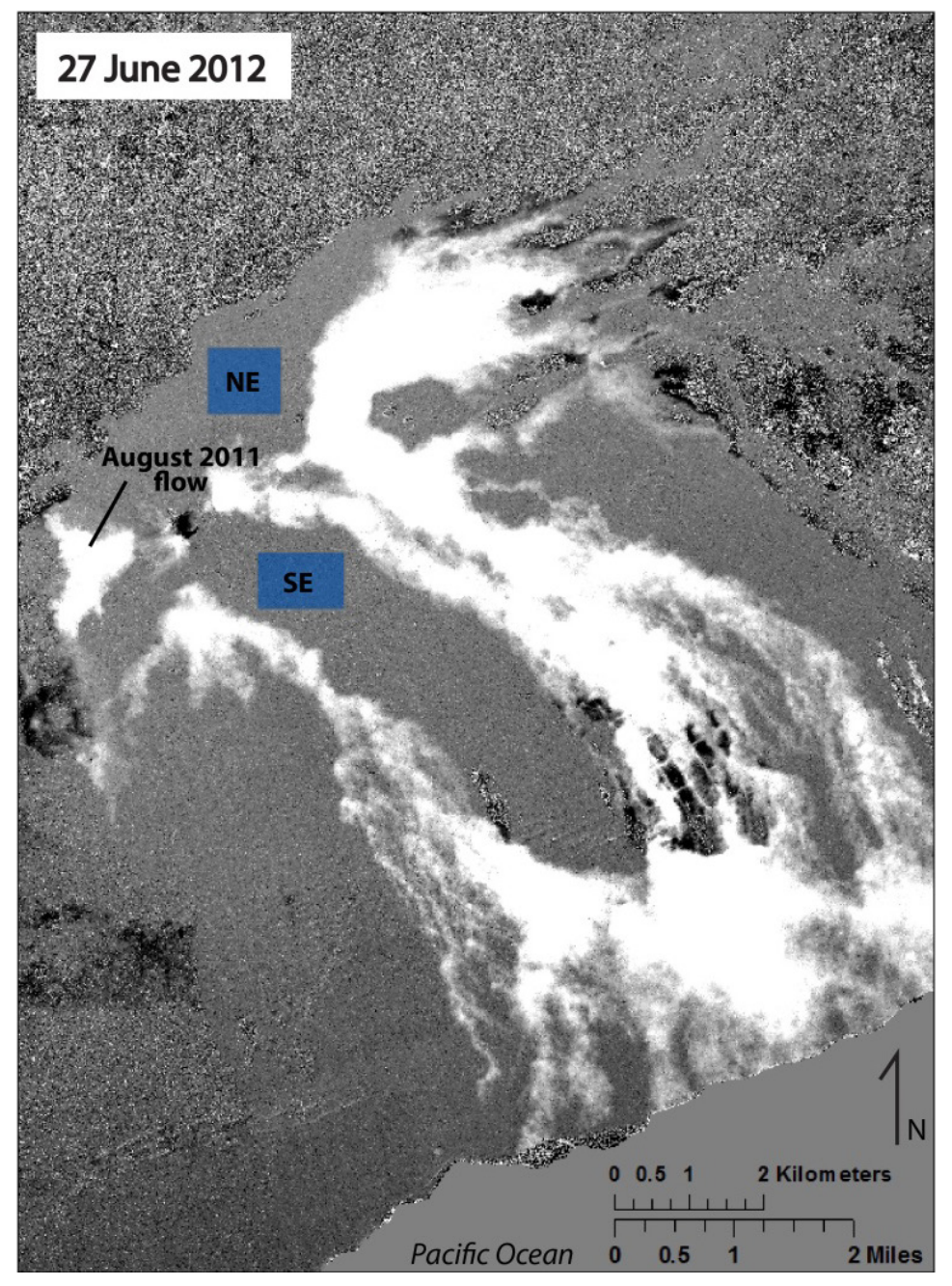

Figure 3.6 TDX DEDM from 27 June 2012 (as shown in Figure 3.5). The blue rectangles represent the areas where statistics were extracted. 
Table 3.1 Statistical analysis of the track 32 flow field DEDMs. All values are in meters.

\begin{tabular}{|c|c|c|c|c|c|c|c|c|c|}
\hline $\begin{array}{l}\text { DEDM } \\
\text { Date }\end{array}$ & $\begin{array}{l}\text { NE } \\
5 \%\end{array}$ & $\begin{array}{c}\text { NE } \\
95 \%\end{array}$ & $\begin{array}{c}\text { NE } \\
\text { Mean }\end{array}$ & $\begin{array}{c}\text { NE } \\
\text { St. Dev. }\end{array}$ & $\begin{array}{l}\text { SE } \\
5 \%\end{array}$ & $\begin{array}{c}\text { SE } \\
95 \%\end{array}$ & $\begin{array}{c}\text { SE } \\
\text { Mean }\end{array}$ & $\begin{array}{c}\text { SE } \\
\text { St. Dev. }\end{array}$ & $\begin{array}{c}\text { Average } \\
\text { Mean }\end{array}$ \\
\hline 20110630 & -4.138 & 3.426 & -0.19436 & 2.44731 & -4.504 & 2.396 & -0.91252 & 2.20800 & -0.55344 \\
\hline 20110813 & -4.861 & 3.128 & -0.71748 & 2.58375 & -5.368 & 2.316 & -1.37586 & 2.45569 & -1.04667 \\
\hline 20110915 & -4.812 & 3.104 & -0.67999 & 2.54828 & -5.573 & 2.327 & -1.44984 & 2.55597 & -1.06491 \\
\hline 20111223 & -2.956 & 3.624 & 0.44962 & 2.09519 & -4.617 & 4.12 & -0.03844 & 2.77694 & 0.20559 \\
\hline 20120125 & -3.922 & 5.627 & 1.00989 & 3.03280 & -5.431 & 6.602 & 0.89398 & 3.78326 & 0.95194 \\
\hline 20120627 & -1.38 & 1.651 & 0.19977 & 0.94900 & -2.355 & 1.304 & -0.42232 & 1.16743 & -0.11127 \\
\hline 20120719 & -1.783 & 1.515 & -0.05092 & 1.03794 & -2.809 & 1.355 & -0.64153 & 1.33694 & -0.34622 \\
\hline 20120730 & -2.236 & 1.827 & -0.10808 & 1.30036 & -2.951 & 1.138 & -0.80179 & 1.30389 & -0.45493 \\
\hline 20120821 & -2.273 & 1.507 & -0.28324 & 1.19653 & -3.086 & 1.296 & -0.79737 & 1.40373 & -0.54030 \\
\hline 20120901 & -2.191 & 1.844 & -0.07458 & 1.27076 & -2.908 & 1.451 & -0.63263 & 1.37175 & -0.35360 \\
\hline
\end{tabular}

If the noise in the ROI is completely random (as we would expect if it comes from the radar scatters), it should have a normal (Gaussian) distribution with a mean of zero. This is not the case with the TDX data, which have histograms that, although symmetrical, are not centered about zero (most are offset by less than 1 meter in the negative).

There are two means in the statistical examination of each DEDM because two test areas were chosen for analysis. The mean pixel values in the ROIs do not correlate well from image to image (i.e., the histogram offsets vary randomly in DEDMs from different dates). However, the means between ROIs in the same DEDM are highly correlated and thus, the means can be averaged and applied as a correction to the whole scene. 

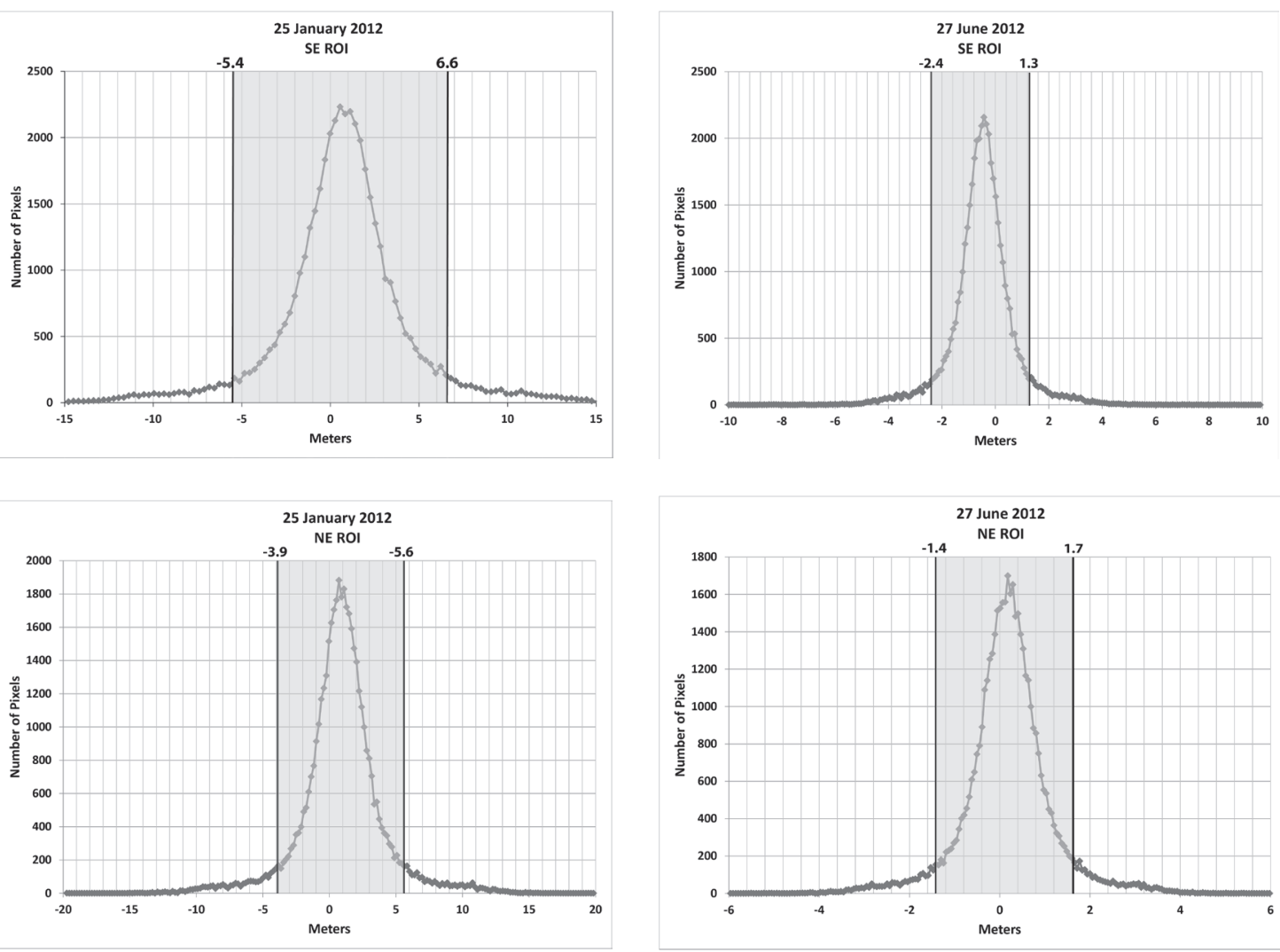

Figure 3.7 Histograms for the DEDMs in Figure 3.5. Note the mean is offset from zero in all four graphs, although the histograms are symmetrical. The area in gray represents the error range, with a $90 \%$ confidence.

Executing a shift correction across the entire DEDM will increase (or decrease) the pixel values uniformly by a specific amount. If this correction is performed on a DEDM used for lava flow modeling, it is unlikely that the revised DEDM will produce a different flow model result, since the correction is uniform. Performing this correction does make a difference, however, when calculating volumes of topographic change between images, which is our reason for making the correction here.

\subsubsection{Volume Calculations}

Estimates of lava flow volumes can be difficult to determine for many volcanoes - even those that are well monitored. For example, the very low frequency (VLF) technique used by Kauahikaua et al. [1996] provides an instantaneous effusion rate for an eruption, but cannot be applied without a suitable active lava tube. If there is pre-eruptive degassing in the system, that can also misrepresent an effusion rate derived from sulfur dioxide emissions [Elias and Sutton, 2012]. 
To test a volume calculation method using the TanDEM-X data, the following steps were used to make a volume estimate of the August 2011 lava flow, using the ArcGIS 10.1 software.

1) Open one TDX DEDM that was acquired before the August 2011 eruption, and one that was acquired after. Using the Raster Calculator tool, subtract one DEDM from the other (in this case, subtract 30 June 2011 from 27 June 2012). This will create a difference map that represents the change in topography between acquisitions (i.e., the August 2011 lava flow).

2) Because we have a detailed map of the flow extent based on field measurements, it can be overlain on the newly created difference map to extract a mask of the area (i.e., cut out the flow area so that it is the only section included in the volume calculation). A TIN (triangulated irregular network) is then constructed from the mask by creating a surface of contiguous, non-overlapping triangles over the lava flow.

3) The Polygon Volume tool is used to calculate the volume of the TIN above and below zero. The volume below zero is not real; it represents the negative portion of the random noise in the data. We subtract the negative volume from the positive volume because our histogram analysis (Figure 3.7) indicates a normal distribution of pixel values. Subtracting the "negative" elevation change will therefore compensate for pixel values that are overestimated (i.e., too positive), and the mean value should be close to the actual volume of the flow (essentially, the high highs and low lows will average out).

4) The volume estimate is corrected for the vertical offset we see in the data (Table 3.1) by multiplying the average mean pixel value for a DEDM by the area of the mask (i.e., the flow area). This gives the volume correction for the area, which is then subtracted from (or added to, as appropriate) the volume from step 3.

In the case of the August 2011 lava flow, the volume of the flow above zero is 12.67 million $\mathrm{m}^{3}$, and below zero is $439,902 \mathrm{~m}^{3}$. Subtracting the two to account for noise, the volume becomes 12.23 million $\mathrm{m}^{3}$. To correct for the data shift, the average mean for the two images is multiplied by the area of the flow field $\left(2.28\right.$ million $\left.^{2}\right)$ and added to the volume. We then multiply this by 0.6 [Cashman et al., 1994] to account for the vesicularity fraction of the lava flow, and the final volume estimate is 7.4 million $\mathrm{m}^{3}$ dense rock equivalent (DRE). Because the uncertainty of the DEDM is high with respect to the thin areas of the flow ( $\pm 3-4$ meters), the uncertainties associated with the volume are also high. Most of the volume estimate comes from the thickest part of the flow, but there is also a large area of thin flow, causing the uncertainty to look disproportionately 
large with respect to the volume. Hence the technique works best on thicker flows ( $>10$ meters).
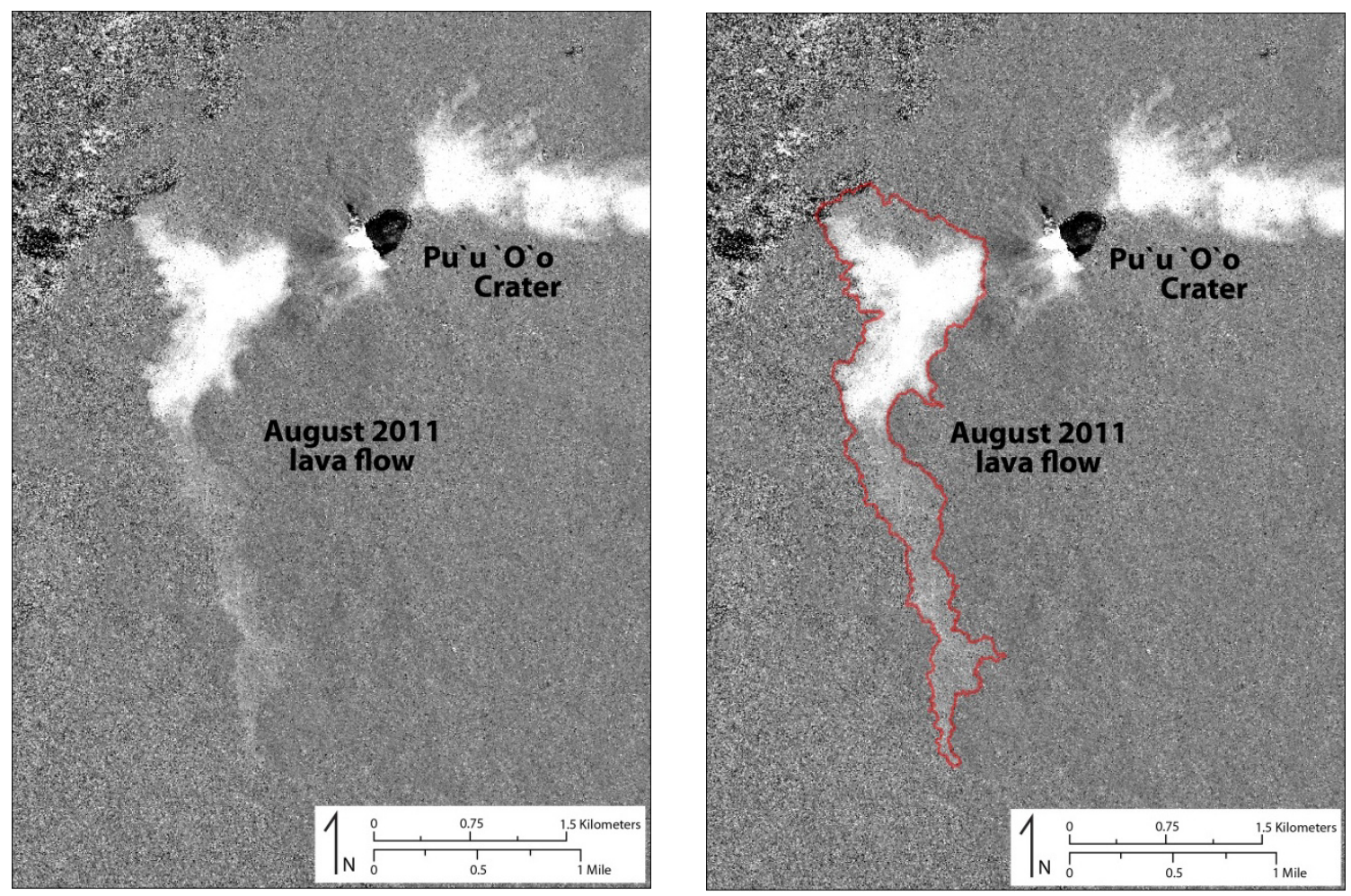

Figure 3.8 Difference DEM created by subtracting the 27 June 2012 DEDM from the 30 June 2011 DEDM. The white area represents the change that occurred between those dates. Right: Actual August 2011 lava flow (based on field mapping) outlined in red. This was used to constrain the area of the DEM used in the volume calculation.

\subsection{MODIS Image Processing}

To run the most accurate lava flow model for the August 2011 eruption, it is essential to use the best lava effusion rate estimates available. This parameter is important because lava flow models forecast the potential extent of lava flows, aiding in hazard planning, warnings, and mitigation. One way to estimate an average eruption rate is to divide the total volume of erupted lava by the eruption duration. Similarly, an average eruption rate can be found by including non-eruptive periods in this calculation [Pieri and Baloga, 1986]. In specific cases where the entirety of lava being discharged is flowing through a lava tube - such as periods of the ongoing $\mathrm{Pu}^{\prime} \mathrm{u}$ ' ${ }^{\prime}{ }^{\prime} \bar{o}-$ Kupaianaha eruption on Kîlauea Volcano - the eruption rate can be calculated using the method of Kauahikaua et al. [1996]. This method utilizes a VLF electromagnetic induction device to estimate the cross-sectional area of a lava tube. The VLF measurements must be taken close to an open skylight and directly over the lava tube so concurrent velocity measurements can be 
taken. This in turn will provide an instantaneous effusion rate. Both of these techniques offer good estimates, but they each have their limits. The VLF technique is limited by the occurrence of a skylight on a single lava tube, as well as personnel and field access limitations. In contrast to an instantaneous effusion rate, when obtaining an eruption rate using the eruption volume, the value is only an average over the time of emplacement of that volume, and is not representative of the entire eruption. This, however, is the only type of ground-based effusion rate measurement we have for the August 2011 eruption, and it only represents the first three hours of effusion (T. Orr and M. Patrick, unpublished data, 2011).

Another valuable way to estimate eruption rates is the use of TIR satellite imagery. While it is the only option for inaccessible volcanoes, it is advantageous for the more accessible volcanoes as well. In fact, use in conjunction with ground data is paramount for model viability and ground truthing. In this study, looking exclusively at MODIS imagery, we implement the technique of Harris et al. [1997b] to estimate time-averaged discharge rates during the August 2011 eruption. The MODIS-derived lava eruption rates are not instantaneous effusion rates at the time of acquisition, but rather average effusion rates up to the time of acquisition [Wright et al., 2001].

MODIS is a sensor located on two different polar-orbiting NASA satellites-Terra and Aqua. The temporal resolution of each sensor is 12 hours, providing a total of four images per day. The images are not, however, equally spaced throughout the day. A timelag of approximately 3-4 hours exists between Terra (overpass at $\sim 10: 30$ am local time) and Aqua (overpass at $\sim 2: 00 \mathrm{pm}$ local time). MODIS is in a near-polar, sun synchronous orbit with cross track scanning. It has 36 bands that cover a range from $620 \mathrm{~nm}$ to 14.385 $\mu \mathrm{m}$ - the visible to the infrared portion of the electromagnetic spectrum. The spatial resolution varies by band: bands $1-2$ are $250 \mathrm{~m}$; bands 3-7 are $500 \mathrm{~m}$; and bands $8-36$ are $1 \mathrm{~km}$. For the purpose of this study, we only look at the imagery in the TIR, and only in band 32 (wavelength 11.77-12.27 $\mu \mathrm{m}$ ). We processed the MOD021KM data, which is Level 1B calibrated radiances at a $1 \mathrm{~km}$ spatial resolution.

Over the 12 day time span of the August 2011 eruption, 42 MODIS images were acquired, but ultimately, only 4 were used in effusion rate calculations. Only raw data were processed due to inconsistencies produced by resampling images during the georeferencing procedure [Oppenheimer et al., 1993]. Daytime images were discarded due to the effects of excess solar radiation on the surrounding lava surface [Harris et al., 1997a]. Cloud cover was the main factor limiting the number of usable images. There were no images entirely free of clouds. In fact, many of the images were obscured with enough cloud that the Big Island could not be located. Numerous other images with slightly less cloud contamination were discarded because the hot spot was not 
distinguishable from the background. Luckily, of the four usable images, none were discarded due to scan-angle distortion effects. Because all of these images were taken from a scan angle of $<50$ degrees, the distortion was minor and they were all processed [Harris et al., 1997b].

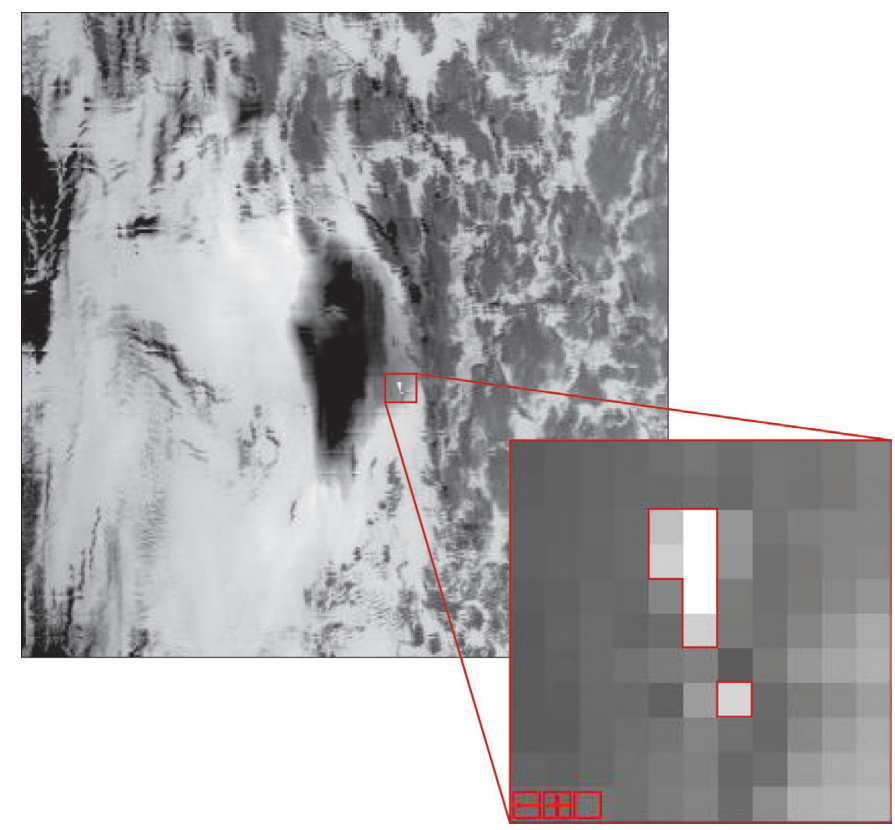

Figure 3.9 A MODIS image (magnified 2x) taken from the Aqua satellite on 5 August 2011 at 1:45 H.S.T. Inset: The red box is magnified $17 \mathrm{x}$, encompassing the hot spot, outlined in red.

\subsubsection{Effusion Rate Calculation}

When evaluating an image, we look for an area with anomalously high radiance values compared to the surrounding area. This is our "hot spot", i.e., area of eruptive activity and active lava. We record the radiance values for each hot (and corresponding background) pixel, and follow the method of Harris et al. [1997b] to estimate a time-averaged discharge rate $\left(\mathrm{E}_{\mathrm{r}}\right)$ :

$$
E_{\mathrm{r}}=\frac{\Phi_{\mathrm{tot}}}{\rho\left(c_{\mathrm{p}} \Delta \mathrm{T}+c_{\mathrm{L}} \Delta \phi\right)}
$$

where $\Phi_{\text {tot }}$ is the total thermal heat flux of the flow, $\rho$ is the lava bulk density (DRE), $c_{p}$ is the lava bulk heat capacity (DRE), and $\Delta \mathrm{T}$ is the temperature difference between the lava temperature at the vent and the temperature at which forward motion is no longer possible $\left(\mathrm{T}_{\text {vent }}-\mathrm{T}_{\text {stop }}\right) . \mathrm{c}_{\mathrm{L}}$ is the latent heat of crystallization, and $\Delta \phi$ is the fraction of crystals grown through $\Delta \mathrm{T}$. This gives us the TADR for the eruption up to the time of acquisition. For all parameter values, refer to Table 3.2. 
By summing the thermal heat flux for each pixel, a total heat flux $\left(\Phi_{\text {tot }}\right)$ is found for the entire flow (active and cooling) over some period of time. This is found by combining the values for radiative heat flux $\left(\Phi_{\text {rad }}\right)$ and convective heat flux $\left(\Phi_{\text {conv }}\right)$ as follows:

$$
\Phi_{\text {tot }}=\Phi_{\text {rad }}+\Phi_{\text {conv }}
$$

To calculate the heat flux from radiation and convection, we use the following equations:

and:

$$
\Phi_{\mathrm{rad}}=A_{\mathrm{c}} \varepsilon \sigma T_{\mathrm{c}}{ }^{4}
$$

$$
\Phi_{\text {conv }}=\mathrm{A}_{\mathrm{c}} \mathrm{h}_{\mathrm{c}}\left(\mathrm{T}_{\mathrm{c}}-\mathrm{T}_{\mathrm{a}}\right)
$$

where $A_{c}$ is the area of the pixel containing active lava, $\varepsilon$ is surface emissivity, $\sigma$ is the Stefan-Boltzmann constant, and $\mathrm{h}_{\mathrm{c}}$ is the convective heat transfer coefficient. $\mathrm{T}_{\mathrm{c}}$ is the assumed temperature for the surface of the active lava, and $\mathrm{T}_{\mathrm{a}}$ is the ambient air temperature. Two end-members (also referred to as the high and low temperature models) are chosen for the lava surface temperature, $T_{c}$, bracketing the final eruption rate calculation into a plausible range for the eruption (see Table 3.2).

When calculating $A_{c}$, a complication due to the 'mixed pixel' problem arises. Because each pixel contains a variety of surface types with an equal variety of surface temperatures, it is known as a mixed pixel. In each mixed pixel, the temperature value for the pixel is actually the weighted average temperature over the entire pixel. For simplicity, we only consider two surface types (temperatures) in the pixel - the hot portion and the cold (ambient) portion. To resolve this, we must find the proportions of the hot and cold temperatures in the pixel. Since we assume temperature values for the end-member models, we calculate the radiance for each temperature model using the Planck Function:

$$
\mathrm{L}_{\lambda}(\mathrm{T})=\frac{2 h \mathrm{c}^{2} \lambda^{-5}}{\left(e^{\frac{h c}{k \lambda T}}-1\right)}
$$

where $h$ is Planck's constant, $\mathrm{c}$ is the speed of light in a vacuum, $\lambda$ is the wavelength of the spectral band used (in this case, the mid-range value for Band 32), $\mathrm{k}$ is the Boltzmann gas constant and $\mathrm{T}$ is the object temperature. 
With the radiances calculated for the two models, the portion of each pixel with active lava $(p)$ can be found using the following equation from Harris et al. [1997a]:

$$
p=\frac{R_{\lambda}-L\left(\lambda, T_{\mathrm{a}}\right)}{L\left(\lambda, T_{\mathrm{h}}\right)-L\left(\lambda, T_{\mathrm{a}}\right)}
$$

where $R_{\lambda}$ is the atmospherically corrected radiance measured from the hot pixel, $L\left(\lambda, T_{a}\right)$ is the radiance of the background (ambient) portion of the pixel, and $L\left(\lambda, T_{h}\right)$ is the radiance of the hot (active) portion of the pixel. From here, the area of the pixel covered by the active lava $\left(\mathrm{A}_{\mathrm{c}}\right)$ is found by:

$$
A_{\mathrm{c}}=p A_{\text {pixel }}
$$

where $A_{\text {pixel }}$ is the area of the pixel.

However, before $A_{c}$ can be calculated, the radiance values for each pixel must first be corrected for emissivity and atmospheric effects. This is necessary because the radiance emitted from the surface of an object is not the value recorded by the satellite's sensor. When radiance from an object passes through the atmosphere, the atmospheric upwelling radiance and variable atmospheric transmissivity can create an incorrect radiance value in the raw data. To correct for this, the following equation from Harris et al. [2011] is used:

$$
R_{\mathrm{TIR}}=\frac{\left(R_{\mathrm{sat}}-R_{\mathrm{up}}\right)}{\tau * \varepsilon}
$$

where $R_{\text {sat }}$ is the at-satellite radiance, $R_{\text {up }}$ is the atmospheric upwelling radiance, $\tau$ is the atmospheric transmissivity, and $\varepsilon$ is surface emissivity. Because reflectance is negligible in the TIR, it is not taken into consideration in this correction. The values for $\mathrm{R}_{\text {up }}$ and $\tau$ were taken from the MODTRAN atmospheric code, and were estimated as a function of scan angle and vent elevation. 
Table 3.2 Input parameters used to calculate effusion rates using MODIS data.

\begin{tabular}{|c|c|c|c|c|}
\hline Parameter & Symbol & Value & Units & Source \\
\hline Surface emissivity & $\varepsilon$ & 0.95 & -- & 2 \\
\hline Planck's constant & $\mathrm{h}$ & $6.63 \times 10^{-34}$ & $\mathrm{~J}$ sec & constant \\
\hline Boltzmann gas constant & $\mathrm{k}$ & $1.38 \times 10^{-23}$ & $\mathrm{~J} \mathrm{deg}^{-1}$ & constant \\
\hline Stefan-Boltzmann constant & $\sigma$ & $5.67 \times 10^{-8}$ & $\mathrm{~W} \mathrm{m^{-2 }} \mathrm{K}^{4}$ & constant \\
\hline Convective heat transfer coefficient & $h_{c}$ & 50 & $\mathrm{~W} \mathrm{~m} \mathrm{~m}^{-2} \mathrm{~K}^{-1}$ & 3 \\
\hline Lava bulk heat capacity (DRE) & $c_{p}$ & 1225 & $\mathrm{~J} \mathrm{~kg}^{-1} \mathrm{~K}^{-1}$ & 2,5 \\
\hline Latent heat of crystallization & $c_{L}$ & $3.5 \times 10^{5}$ & $\mathrm{~J} \mathrm{~kg}^{-1}$ & 5 \\
\hline Crystallization fraction* & $\Delta \varphi$ & $0.45,0.02$ & -- & 5 \\
\hline $\mathrm{T}_{\text {vent }}-\mathrm{T}_{\text {stop }} *$ & $\Delta \mathrm{T}$ & 385,150 & $\mathrm{~K}$ & 2 \\
\hline Vesicularity fraction* & $\mathrm{v}$ & $0.1,0.7$ & -- & 1 \\
\hline Lava bulk density (DRE)* & $\rho$ & 2484,828 & $\mathrm{~kg} \mathrm{~m}^{-3}$ & 4 \\
\hline Low temperature model & $\mathrm{T}$ & 100 & ${ }^{\circ} \mathrm{C}$ & 5 \\
\hline High temperature model & $\mathrm{T}$ & 500 & ${ }^{\circ} \mathrm{C}$ & 5 \\
\hline Ambient air temperature & $\mathrm{T}_{\mathrm{amb}}$ & 25 & ${ }^{\circ} \mathrm{C}$ & 2 \\
\hline Wavelength & $\lambda$ & 12.02 & $\mu \mathrm{m}$ & calculated \\
\hline
\end{tabular}

Table 3.3 provides the TADRs derived from the method above. Due to data quality, the first value was not available until approximately 1.5 days after the eruption began. The eruption rates available spanned the first half of the eruption, which covered the times of highest effusion rate. It is important to note that these TADRs are averaged over a number of days, so they will, in some cases, be substantially lower than the volume estimates given by HVO, which were only averaged over a number of hours at the start of the eruption. Both the high- and low-temperature model rates are presented in Table 3.3. We expect that the actual eruption rate at the time of acquisition lies somewhere in between the two models, but we prefer to use the high temperature model because it gives more realistic results, given that an active, channel-fed flow is probably closer to 500 than $100{ }^{\circ} \mathrm{C}$.

Table 3.3 Time-averaged discharge rates for the August 2011 eruption, derived from MODIS satellite imagery.

\begin{tabular}{lcc}
\hline $\begin{array}{c}\text { Acquisition Date and } \\
\text { Time (H.S.T.) }\end{array}$ & $\begin{array}{c}\text { Eruption Rate }\left(\mathbf{m}^{\mathbf{3}} \mathbf{s}^{-\mathbf{1}}\right) \\
\text { Low Temperature Model }\end{array}$ & $\begin{array}{c}\text { Eruption Rate }\left(\mathbf{m}^{\mathbf{3}} \mathbf{s}^{\mathbf{- 1}}\right) \\
\text { High Temperature Model }\end{array}$ \\
\hline 4 August 2011 at 23:00 & 2.24 & 18.80 \\
5 August 2011 at 1:45 & 7.46 & 61.33 \\
6 August 2011 at 2:25 & 5.83 & 48.06 \\
8 August 2011 at 22:35 & 12.68 & 103.95 \\
\hline
\end{tabular}


Our estimates of lava effusion rates from both ground estimates and satellite imagery, as well as the up-to-date TDX DEMs, can be combined to model the August 2011 eruption. To accomplish this we use the FLOWGO model [Harris and Rowland, 2001] combined with the DOWNFLOW model of Favalli et al. [2005].

\subsection{Lava Flow Modeling}

FLOWGO is a self-adaptive, thermo-rheological numerical model for lava flowing in a channel [Harris and Rowland, 2001]. It is a cooling-limited model that calculates the downflow heat and velocity loss, and consequent rheological change, as lava moving down a channel begins to cool and crystallize. The model will continue to propagate the lava channel until the flow can no longer move (Figure 3.10).

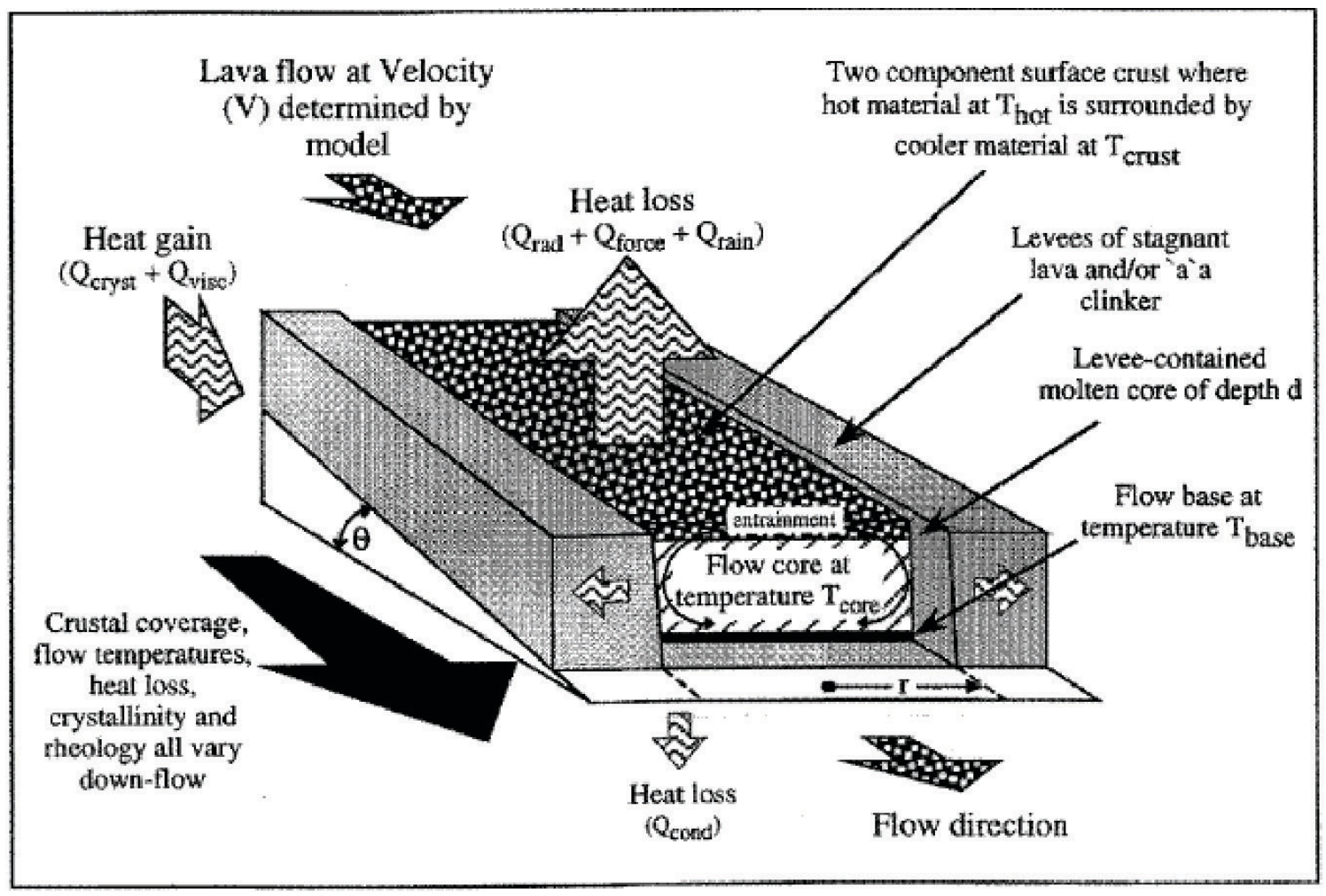

Figure 3.10 A summary schematic of the FLOWGO model. Figure taken from Harris and Rowland [2001]. See Appendix D for documentation of permission to republish this material.

As described by Harris and Rowland [2001], this model can be used to (a) analyze lava flow thermo-rheological relationships; (b) identify the important factors that determine how far a channel-fed flow can extend; (c) assess lava flow hazards; and (d) reconstruct flow regimes at prehistoric, unobserved, or remote flows. In this project, we focus on reconstructing the August 2011 lava flow using two DEMs of different resolutions and 
produced at different times to assess their validity and effectiveness in lava flow hazard assessments.

According to Harris and Rowland [2001], four assumptions are made to simplify the FLOWGO model. First, the lava channel must flow between two stagnant levees, with one free surface in contact with the atmosphere. Next, conservation of mass is maintained by adjusting the channel dimensions after each successive increment. The channel dimensions are dependent on velocity, so when the velocity decreases, the channel width increases. The third assumption states that a control volume (i.e., a lava parcel) will begin at a distance behind the flow front. This allows for a complete thermal and structural evolution of the lava parcel down channel. Finally, the model assumes a three-component vertical thermal structure in the channel: surface, core, and base. The surface component consists of a chilled, broken crust, exposing high-temperature material in its cracks. The core is the high temperature interior component, and the base consists of a cooler, basal crust.

FLOWGO contains a large number of constants and variables. Before each run, the user can input parameters for the specific eruption of their choice. For example, the user can enter the effusion rate, lava eruption temperature, vesicularity, lava density, and channel dimensions. If no parameters are entered, the model will run on the default parameters, which are calibrated for the 1984 Mauna Loa eruption. Once the eruption data have been entered, the model sends a control volume of lava down the channel, recalculating the thermal and rheological properties after each $1-\mathrm{m}$ increment. The model will continue to update these values until the flow velocity reaches zero, or the core lava temperature reaches the solidus.

Modeling the cooling limit of a single lava channel is a useful tool, but applying a stochastic approach to this model can produce a good representation of an eruption flow field. This approach can also be used to produce a probabilistic lava flow hazard map, although this program does not have that capability. For each individual run, the model starts with the pixel containing the vent location, then looks at each adjacent pixel on the DEM to determine the path of steepest descent. By using the stochastic approach of DOWNFLOW [Favalli et al., 2005], for each iteration, all pixel elevations are varied randomly by a range set by the user (i.e., DEM noise). This creates a slightly different flow line each time. By running the model enough times, a set of possible flow paths are produced, creating a nice reproduction of a theoretical flow field. The DEM noise parameter in this model is different from the inherent noise in the original DEM, and the two should not be confused. 
A DEM and co-registered image in ENVI standard format are needed to run the program. FLOWGO reads the DEM and projects the modeled flow paths on the accompanying image. The final output is an image with the flow lines superimposed. In the single flow model, the data are written to a text file, but in the stochastic flow model, the only output is the image.

As described above, there are two options when running the FLOWGO model: a single flow line model and an iterative "loop" model to simulate an entire flow field. The initial steps for both models are the same. First, locate the vent you wish to model and find the corresponding pixel on the co-registered image in FLOWGO. Next, use the "Drain" function to predict the flow's path to the edge of the DEM, based on the line of steepest descent. This is represented by a yellow line on the image (e.g., Figures 3.11, 3.12). To estimate how far the control volume, erupted at a given effusion rate, will extend down the path, thermo-rheological parameters must be changed to suit the individual eruption. Once the parameters are set, the model displays a red line defining the distance the control volume will reach before cooling prevents any further motion. For each individual run, the channel length, elapsed time, volume, effusion rate, velocity, and Reynolds number are written to a text file. To run the loop model, the user must input additional information: the number of iterations to execute, the starting effusion rate, the maximum DEM noise, and the channel aspect ratio.

\subsubsection{Modeling Results}

The August 2011 eruption was modeled on two DEMs of different resolutions. The aim was to evaluate the accuracy of the flow model on each DEM, then compare the results of each to investigate how DEM resolution affects the model. Since we have a detailed map of the August 2011 flow, the model results can be validated by actual data. The two DEMs used in the model were the 2000 SRTM DEM and an updated 2011 TanDEM-X DEM generated using the procedure described above (Section 3.1.2). The spatial resolutions of the DEMs are 30 meters and 4.5 meters, respectively.

Only a few of the FLOWGO model parameters were modified for the August 2011 eruption, due to the similarity of Mauna Loa and Kîlauea volcanoes (see full list of parameters and values in Appendix B). The following values were used in both the SRTM and TDX runs: an ambient air temperature of 25 degrees $C$ [Harris et al., 1998]; a vesicularity fraction of 0.4 [Cashman et al., 1994]; and a dense rock density of $2760 \mathrm{~kg}$ $\mathrm{m}^{-3}$ [Thornber et al., 2003]. The only model parameter that was not consistent in both DEMs was the DEM noise. DEM noise of 3 meters was used with the SRTM DEM while 1 meter was used with the TDX DEM. The reason for this discrepancy is explained in more detail below. 
The lava effusion rates used in the model were either derived from MODIS satellite imagery (section 3.2.1), or provided by a HVO geologist. The range of effusion rate estimates was large-spanning $19-333 \mathrm{~m}^{3} \mathrm{~s}^{-1}$. The lower effusion rates $\left(19-104 \mathrm{~m}^{3} \mathrm{~s}^{-1}\right)$ were derived from MODIS, and represent several TADRs, i.e., the average effusion rate from the beginning of the eruption to the time the image was acquired. The higher estimates (111-333 $\left.\mathrm{m}^{3} \mathrm{~s}^{-1}\right)$ originated from an estimate of the flow volume over the first few hours of the eruption. These rates are higher because they are averaged over a shorter period of time during the eruption, and the eruption rate slowed down after the initial surface breakout. For reference, the following effusion rates were modeled with FLOWGO: $19 \mathrm{~m}^{3} \mathrm{~s}^{-1}, 48 \mathrm{~m}^{3} \mathrm{~s}^{-1}, 61 \mathrm{~m}^{3} \mathrm{~s}^{-1}, 104 \mathrm{~m}^{3} \mathrm{~s}^{-1}, 222 \mathrm{~m}^{3} \mathrm{~s}^{-1}$, and $333 \mathrm{~m}^{3} \mathrm{~s}^{-1}$.

\section{SRTM Runs}

On the SRTM DEM, FLOWGO was programmed to run 100 iterations at each of the given effusion rates. The DEM noise was set to $3 \mathrm{~m}$, enabling the program to cover 100 potential flow paths within a 3 meter vertical window, and attempt to recreate the August 2011 flow field (see Figure 3.11). After running all of the known effusion rate estimates through the model, $48 \mathrm{~m}^{3} \mathrm{~s}^{-1}$ produced the best match, in length and area, to the actual flow field (Figure 3.11, lower right). When using a larger effusion rate value, such as 104 $\mathrm{m}^{3} \mathrm{~s}^{-1}$, the same width and flow path are followed, but the flow lines travel farther from the vent before they stop. Even though $104 \mathrm{~m}^{3} \mathrm{~s}^{-1}$ is a reasonable and realistic effusion rate estimate for the first few hours of the eruption, the actual flow did not reach the distance predicted by the model. This discrepancy can be attributed to the nature of FLOWGO, which is a cooling-limited, rather than volume-limited model. The high effusion rate estimates were likely reached in the eruption, but did not last long enough to produce flows that would attain the distances predicted by the model. In fact, the main spatial extent of the flow field was emplaced within the first few hours of eruption (T. Orr and M. Patrick, unpublished data, 2011), so the effusion during the latter part of the eruption did not significantly increase the flow field area.

A closer look at the models in Figure 3.11 shows that, although the effusion rate of $48 \mathrm{~m}^{3}$ $\mathrm{s}^{-1}$ provided the best match to the actual August 2011 flow, the trajectory was quite different from the model. Moreover, it appears that the August 2011 flow is topographically controlled, at least to the east, by the flow lines produced in the model. Because the SRTM DEM used in the model is from 2000, it is severely out of date. From the time the DEM was created to the time of the August 2011 eruption, many lava flows were emplaced on the flow field. This suggests that the models we see in Figure 3.11 are modeling the August 2011 eruption as if the previous lava flows were not there. In fact, the entire extent covered by the modeled flow lines contains topography from lava flows emplaced between the creation of the SRTM DEM and the TDX DEM. This is an 
excellent example that shows the importance of regularly updating DEMs, especially in areas that encounter constant change, for more accurate flow modeling.
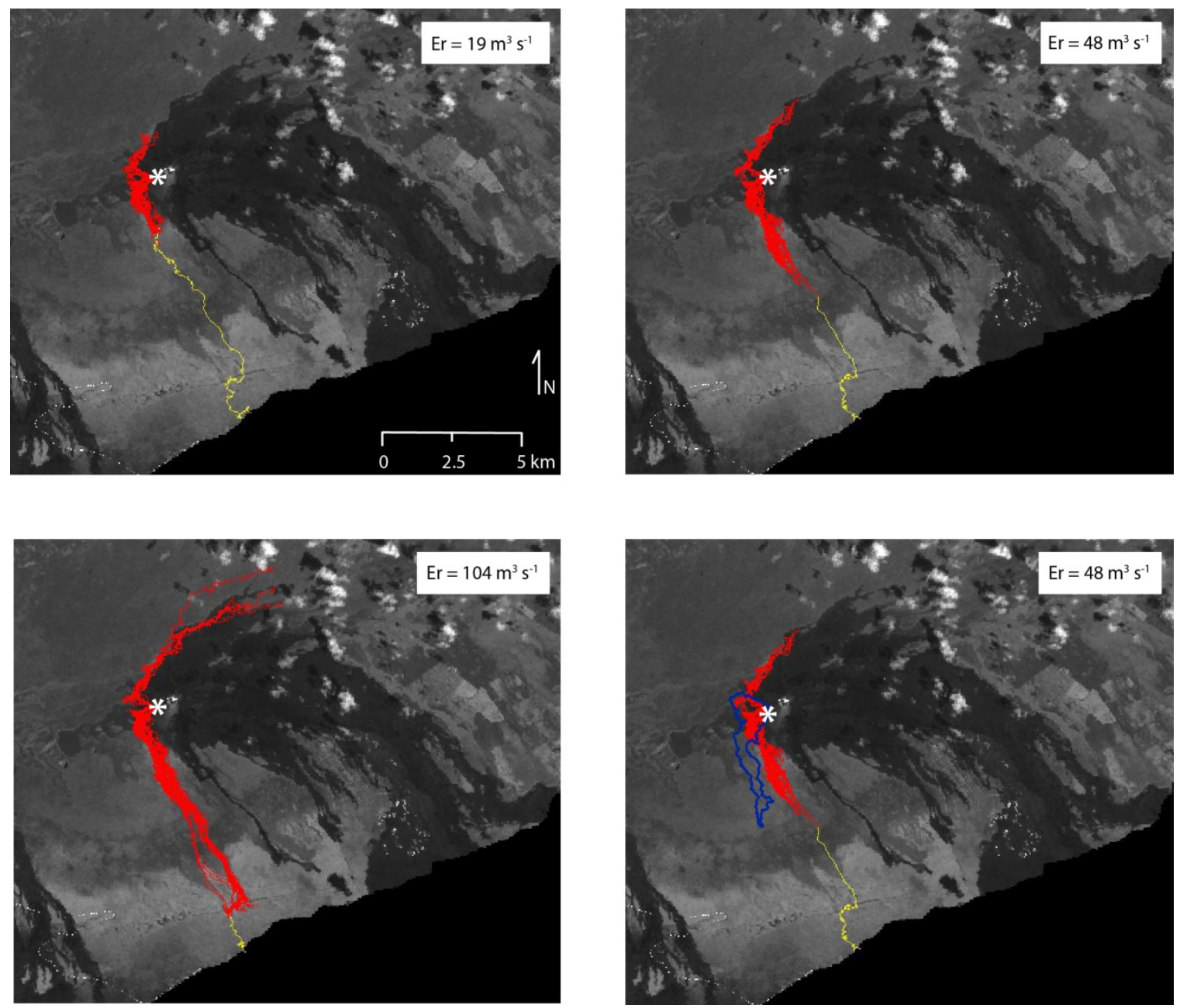

Figure 3.11 FLOWGO model projections of the August 2011 lava flow on the 2000 SRTM

DEM. Each flow model was run with 100 iterations. The red lines represent possible flow paths at the given effusion rate, and the yellow line represents the line of steepest descent. The white asterisk represents the eruption vent. Lower right: The field-mapped August 2011 flow outline is overlain on the model in blue.

\section{TanDEM-X runs}

Many TanDEM-X DEMs spanning different time periods were created during this study, but the 30 June 2011 DEM was chosen as input for the FLOWGO model because it represents the most recent surface topography immediately before the August 2011 eruption. The TDX DEDM was added to the 2005 IfSAR DEM to create the up-to-date DEM we use in the model. 
Unfortunately, FLOWGO currently has limited capabilities when it is run on a high resolution DEM. It is not equipped to handle the increased data allowance and higher noise values in both the IfSAR and TDX DEMs. The program only has a 100,000 point profile maximum and therefore crashes when the DEM noise exceeds 1 . This makes it impossible to use the iterative function of the program. Because the TDX and IfSAR DEMs are very large, the DEM was subset to a smaller area surrounding the vent to reduce the size. A speckle-smoothing filter was also used in an attempt to reduce the noise, but the program crashes nonetheless.

Since the functional options were limited in FLOWGO, we only ran single-line flow models using the TDX data. Using the same effusion rates as above, the model produced drastically different results. As shown in Figure 3.12, lava flow lengths were much shorter than obtained with the SRTM runs. This major discrepancy can only be due to the noise within the DEM itself. In the single-line model, the flow follows the trajectory of the line of steepest descent. Because the TDX DEM has so many more pixels than the SRTM DEM, the model encounters 36 times the noise. Within the small elevation variations between pixels of several meters, the flow has to fill in the lows (holes) before it can move to the next pixel. Due to the cooling-limited nature of FLOWGO, the model uses all of its "energy" cooling the flows while filling in these holes. If these holes actually existed in reality and were not attributed to noise in the DEM, the flow line predicted by the model would be correct. However, the holes are a byproduct of the error in the DEM and therefore create a "false" topography for the model to process. This explains why the flow line stops at a much shorter distance on the TDX DEM. In fact, the only way to create a flow that reaches the actual flow distance is to increase the effusion rate to at least $2000 \mathrm{~m}^{3} \mathrm{~s}^{-1}$. In reality, this is unreasonably high and is only used to demonstrate how the DEM noise affects the model.

In contrast to the SRTM DEM, the TDX DEM is up-to-date, representing the flow field about a month before the eruption began. Using the most recent DEM, as shown in Figure 3.12, is clearly more accurate than the older SRTM DEM. The flow line in the model, which represents the line of steepest descent, aligns almost perfectly with the actual flow and stays within the flow boundary the majority of the time. Once all of the upgrades to FLOWGO have been implemented (in progress), it will have the potential to provide a more accurate flow model on high-resolution DEMs. 

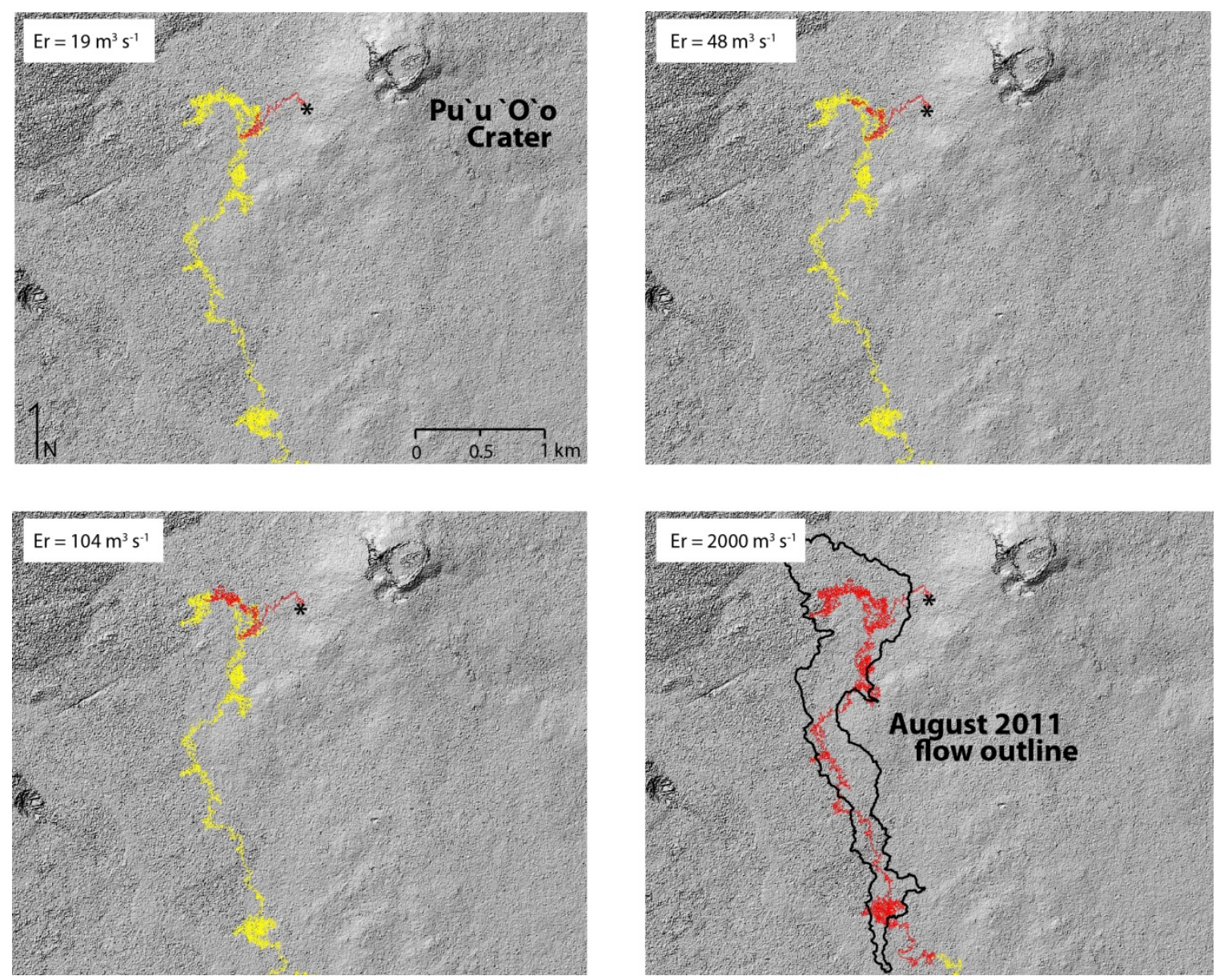

Figure 3.12 FLOWGO model projections for the August 2011 lava flow on a TanDEM-X DEM. The red line is the single flow line produced by the model at the given effusion rate. The yellow line is the line of steepest descent on the DEM and the black asterisk represents the vent. The flow line in each model is drastically affected by the amount of noise in the DEM and does not represent a realistic eruption at its respective effusion rate. The effusion rate that best fits the August 2011 flow is unrealistic and was found by trial and error.

\section{Discussion and Conclusions}

We have shown the importance of accurate topography in lava flow models, as well as the need for frequent updates of DEMs at persistently active volcanoes such as Kîlauea. Currently, the time delay between a TanDEM-X data acquisition and data availability is a few months. Hopefully, as the data are used in more studies, results will begin to show the importance of rapid access and reduce the time lag (especially for emergencies) between acquisition and availability. The time interval between acquisitions for the Kîlauea tracks is approximately 1-3 months, so a new DEM can potentially be created for 
the volcano up to several times per year. This is a breakthrough for areas that experience prolonged lava flows such as Killauea, where the DEM needs constant updates.

Since the TDX DEMs are created using a space-borne SAR, the DEMs are noisy and may cause problems with some lava flow models. Attempts can be made to reduce the noise, such as averaging multiple passes of the satellite over the same area using different look angles [Krieger et al., 2007], but this is done on a longer time scale, so it is not an option for this study. Another option is to apply various different filters to the data. This may help to reduce the noise, but should only be used if it does not degrade the "real" topography in the data.

Unfortunately, because of the noise inherent in the TDX DEMs, as well as the age of the SRTM DEM, the results of modeling the August 2011 eruption using FLOWGO are not directly comparable. The noise in the TDX DEM reduced the functionality of the FLOWGO model, creating a "false" topography and overloading the profile maximum, so the flow runs were not viable. The model outputs on the SRTM DEM provided more realistic results, but because the DEM was out of date, it created a different type of "false" topography for the model.

So, the next important question becomes, "What is the most optimum resolution for a DEM used in flow modeling?" After examining the results of the two DEMs using the FLOWGO model, it is still not certain. More studies are needed on the high resolution TDX DEMs, as well as other DEMs of intermediate resolutions, to constrain the optimum resolution for lava flow modeling. In this study, the high resolution of the TDX DEM exceeded the capabilities of the FLOWGO model, but the model could be adapted to cope with larger datasets. This problem may not be exclusive to FLOWGO. All models that utilize a DEM in their calculations must be capable of handling large amounts of data, because technology will continue to improve data quality.

As the data increases in size and resolution, it is also important to constrain the lower limit to the task it will undertake. For example, is a DEM with 1-meter resolution needed for a lava flow model? What kind of problems might such a high resolution cause, and how will it affect the flow model? What might the DEM look like in a forested area where the height of the treetops, rather than the ground, is represented? Perhaps more importantly, at what point does the resolution no longer make a difference in the lava flow model? There may be no difference in a 1 meter versus 3 meter resolution DEM if the lava flow being modeled is, for example, 10 meters across and 5 meters thick.

As more sophisticated instruments become available for research, higher data quality will follow. This will, in turn, help us to provide more accurate hazard assessments, to the best of our ability. 


\section{Future Work}

Applications for the TanDEM-X data have enormous potential, well beyond the scope of this study. The TDX DEMs can be used to map lava flows, or to make more sophisticated volume calculations when coupled with other data sets. For example, we can look at incoherent areas (areas of change, such as the emplacement of a lava flow) between SAR acquisitions and create a mask of those areas. Then we can use the incoherence mask as an indicator of the flow area, eliminating the need for a detailed map of the flow boundary. We can also create a difference DEM over the period between SAR acquisitions, and using that DEDM, calculate the volume within the incoherence mask (i.e., the volume of the lava flow).

A more robust model is also needed to test different DEMs for an optimum resolution in flow modeling. Once an appropriate model is chosen, more flow validation will also be needed, using well-constrained lava flows such as the August 2011 flow. Experimenting with different filters on the TDX data may also help to smooth the DEM noise and improve the model results. 


\section{References}

Cashman, K. V., M. T. Mangan, and S. Newman (1994), Surface degassing and modifications to vesicle size distributions in active basalt flows, J. Volcanol. Geotherm. Res., 61, 45-68.

During, R., F. N. Koudogbo, and M. Weber (2008), TerraSAR-X and TanDEM-X: Revolution in Spaceborne Radar, The International Archives of the Photogrammetry, Remote Sensing and Spatial Information Sciences, XXXVII, part B1, Beijing.

Elias, T., and A. J. Sutton (2012), Sulfur dioxide emission rates from Kīlauea Volcano, Hawai ‘i, 2007 2010, U.S. Geological Survey Open-File Report 2012-1107, 25 p. (Available at http://pubs.usgs.gov/of/2012/1107/).

Farr, T. G., P. A. Rosen, E. Caro, R. Crippen, R. Duren, S. Hensley, M. Kobrick, M. Paller, E. Rodriguez, L. Roth, D. Seal, S. Shaffer, J. Shimada, and J. Umland (2007), The Shuttle Radar Topography Mission, Rev. Geophys., 45, RG2004, doi:10.1029/2005RG000183.

Favalli, M., M. T. Pareschi, A. Neri, and I. Isola (2005), Forecasting lava flow paths by a stochastic approach, Geophys. Res. Lett., 32, L03305, doi:10.1029/2004GL021718.

Ferretti, A., A. Monti-Guarnieri, C. Prati, F. Rocca, and D. Massonnet (2007), Part A Interferometric SAR image processing and interpretation, in InSAR principles: Guidelines for SAR Interferometry Processing and Interpretation, TM-19, ESA Publications, The Netherlands, edited by K. Fletcher, pp. A1-A40.

Fritz, T., C. Rossi, N. Yague-Martinez, F. Rodriguez-Gonzalez, M. Lachaise, H. Breit (2011), Interferometric processing of TanDEM-X data, German Aerospace Center (DLR), IGARSS 2011.

Goldstein, R., and C. L. Werner (1998), Radar interferogram filtering for geophysical applications, Geophys. Res. Lett., 25(21), 4035-4038.

Harris A. J. L., A. L. Butterworth, R. W. Carlton, I. Downey, P. Miller, P. Navarro, D. A. Rothery (1997a), Low-cost volcano surveillance from space: case studies from Etna, Krafla, Cerro Negro, Fogo, Lascar and Erebus, Bull. Volcanol., 59, 49-64.

Harris, A. J. L., S. Blake, and D. A. Rothery (1997b), A chronology of the 1991 to 1993 Mount Etna eruption using advanced very high resolution radiometer data: Implications for real-time thermal volcano monitoring, J. Geophys. Res., 102, B4, 7985-8003.

Harris, A. J. L., L. P. Flynn, L. Keszthelyi, P. J. Mouginis-Mark, S. K. Rowland, J. A. Resing, (1998), Calculation of lava effusion rates from Landsat TM data, Bull. Volcanol., 60, 52-71.

Harris, A., and S. K. Rowland (2001), FLOWGO: a kinematic thermo-rheological model for lava flowing in a channel, Bull. Volcanol., 63, 20-44, doi: 10.1007/s004450000120.

Harris, A., A. Steffke, S. Calvari, and L. Spampinato (2011), Thirty years of satellite-derived lava discharge rates at Etna: Implications for steady volumetric output, J. Geophys. Res., 116, B08204, doi: 10.1029/2011JB008237. 
Harris, A. (2013), Thermal Remote Sensing of Active Volcanoes: A User's Manual, Cambridge University Press, New York.

Kauahikaua, J., M. Mangan, C. Heliker, and T. Mattox (1996), A quantitative look at the demise of a basaltic vent: the death of Kupaianaha, Kilauea Volcano, Hawai' i, Bull. Volcanol. 57, 641-648.

Kauahikaua, J. (2007), Lava Flow Hazard Assessment, as of August 2007, for Kilauea East Rift Zone Eruptions, Hawai'i Island, U.S. Geological Survey Open-File Report 2007-1264, 9 p., (Available at http://pubs.usgs.gov/of/2007/1264/).

Keszthelyi, L., A. J. L. Harris, and J. Dehn (2003), Observations of the effect of wind on the cooling of active lava flows, Geophys. Res. Lett., 30(19), 1989, doi: 10.1029/2003GL017994.

Krieger, G., H. Fiedler, I. Hajnsek, M. Eineder, M. Werner, and A. Moreira (2005), TanDEM-X: Mission Concept and Performance Analysis, International Geoscience and Remote Sensing Symposium, 7, 4890 .

Krieger, G., A. Moreira, H. Fielder, I. Hajnsek, M. Werner, M. Younis, and M. Zink (2007), TanDEM-X: A Satellite Formation for High-Resolution SAR Interferometry, IEEE Transactions on Geoscience and Remote Sensing, 45(11), 3317-3338.

Oppenheimer, C., P. W. Francis, D. A. Rothery, and R. W. T. Carlton (1993), Infrared Image Analysis of Volcanic Thermal Features: Lascar Volcano, Chile, 1984-1992, J. Geophys. Res., 98, B3, 42694286.

Pieri, D. C., and S. M. Baloga (1986), Eruption rate area, and length relationships for some Hawaiian lava flows, J. Volcanol. Geotherm. Res., 30, 29-45.

Thornber C. R., C. Heliker, D. R. Sherrod, J. P. Kauahikaua, A. Miklius, P. G. Okubo, F. A. Trusdell, J. R. Budahn, W. I. Ridley, and G. P. Meeker (2003), Kilauea East Rift Zone Magmatism: An Episode 54 Perspective, J. Petrol., 44(9), 1525-1559, doi: 10.1093/petrology/egg048.

Werner, C., U. Wegmuller, T. Strozzi, and A. Wiesmann (2000), GAMMA SAR and Interferometric Processing Software, ERS - ENVISAT Symposium, Gothenburg, Sweeden, 16-20 Oct. 2000.

Wright, R., S. Blake, A. J. L. Harris, D. A. Rothery (2001), A simple explanation for the space-based calculation of lava eruption rates, Earth Planet. Sci. Lett., 192, 223-233. 


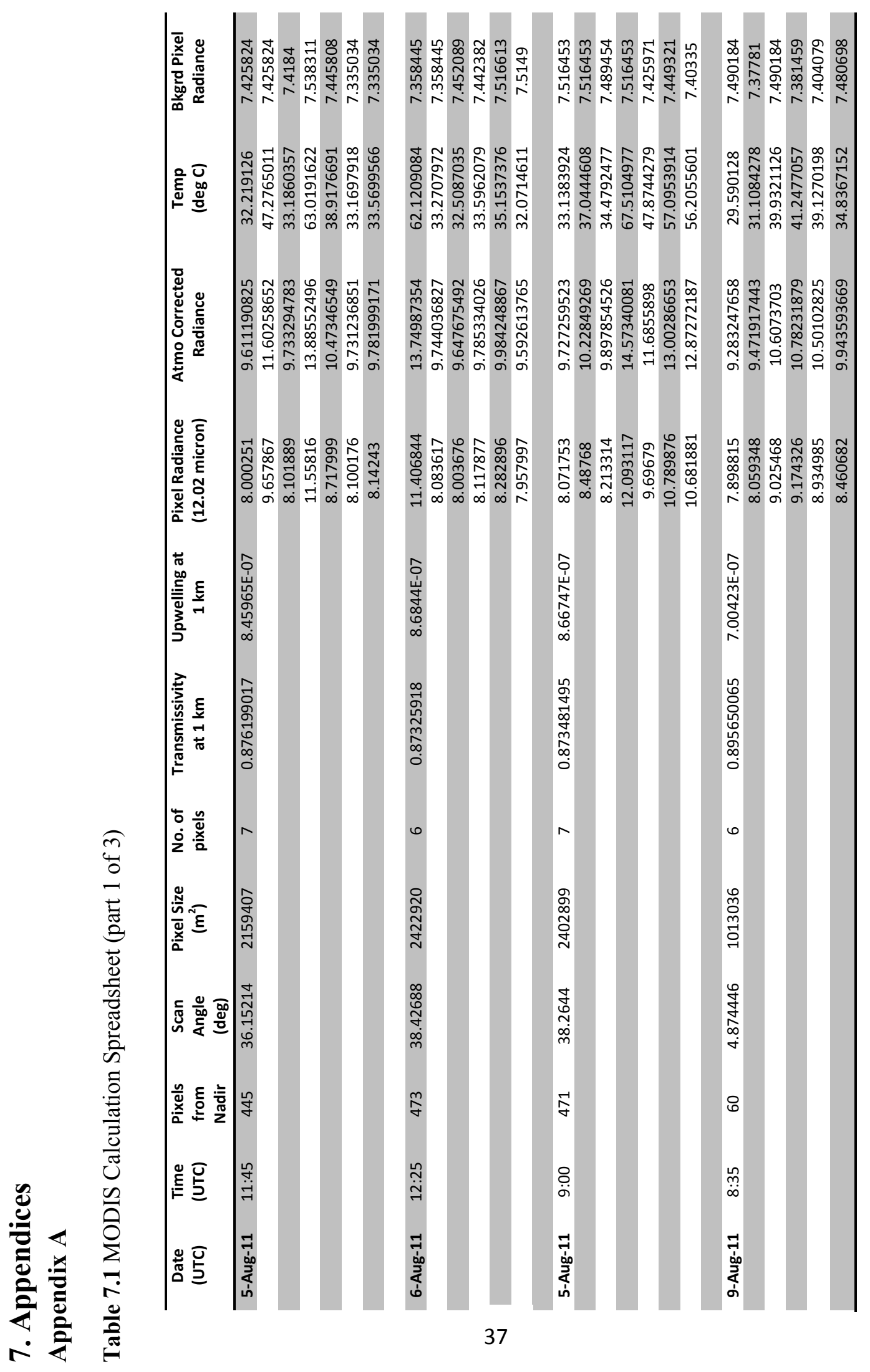




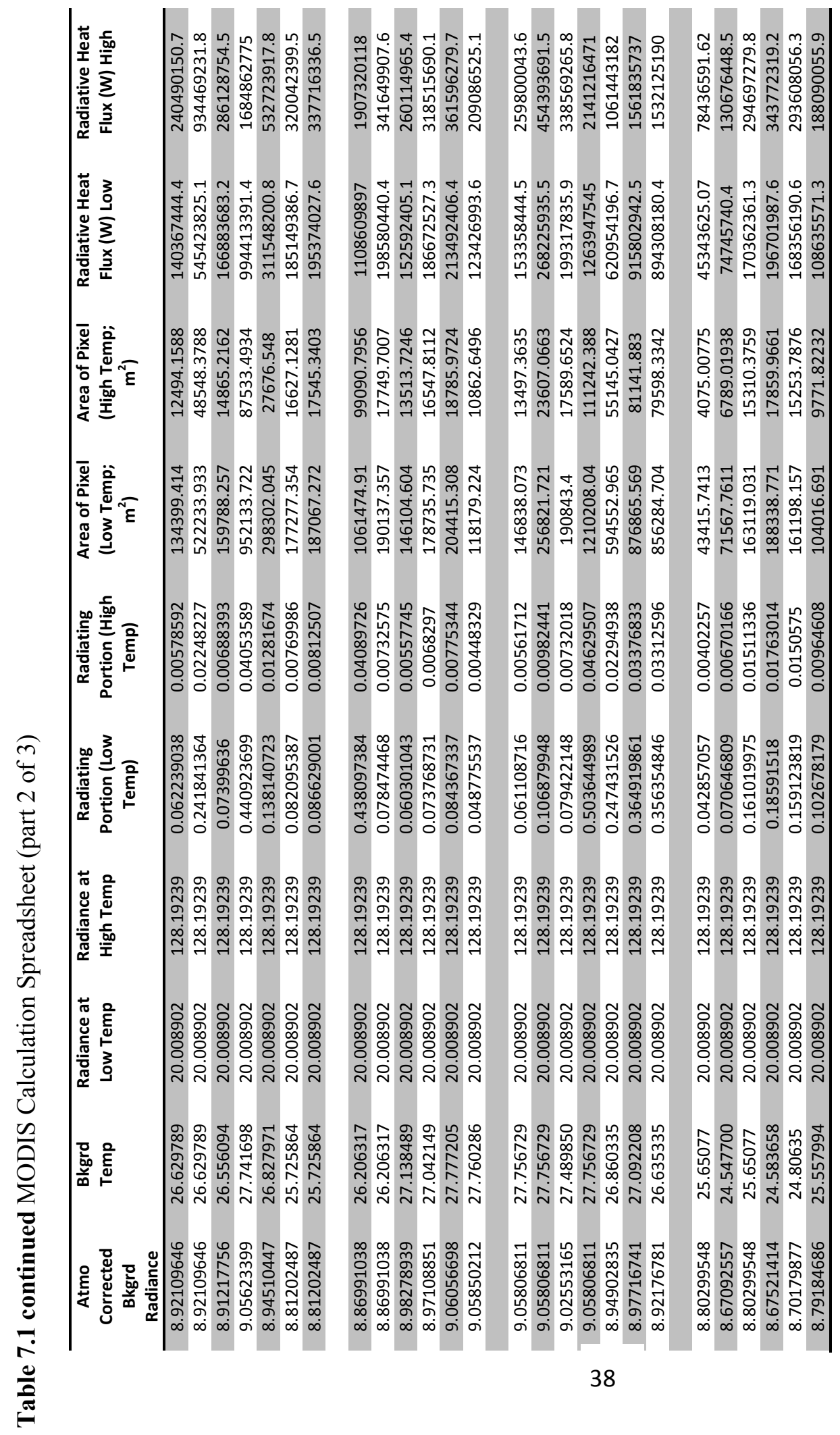




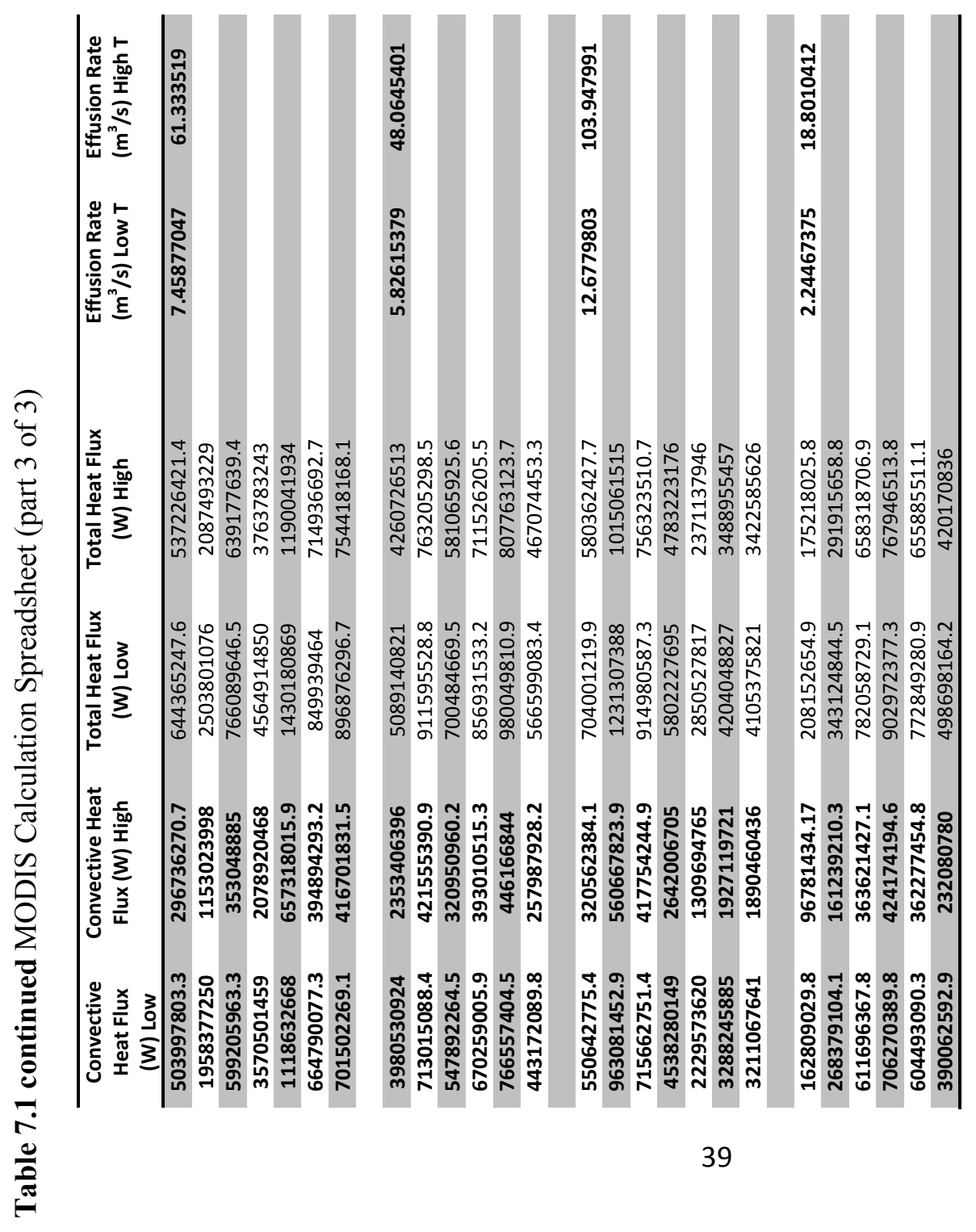




\section{Appendix B: FLOWGO Model Parameters for the August 2011 Eruption}

\section{CONSTANTS}

Gravitational acceleration $\left(\mathrm{m} \mathrm{s}^{-2}\right)$

YIELD STRENGTH (Dragoni, 1989)

A1

A2

B1

\section{CHANNEL DIMENSIONS}

Width (m)

Depth (m)

Step Distance $(\mathrm{m})$

Spatial frequency for dumping values to output file (m)

\section{TEMPERATURE PARAMETERS}

Eruption Temp $\left({ }^{\circ} \mathrm{C}\right)$

Solidus temp $\left({ }^{\circ} \mathrm{C}\right)$

Core $\mathrm{T}$ - max surface $\mathrm{T}\left({ }^{\circ} \mathrm{C}\right)$

CRUST TEMPERATURE MODEL

Model 0: Tcrust independent of fcrust

Model 1: Tcrust depends on fcrust

Model for calculation of crust temperature

At-vent crust temperature $\left({ }^{\circ} \mathrm{C}\right)$

CRUST GROWTH MODEL OPTIONS

Model 1: Light crust growth model

(poor insulation)

Model 2: Heavy crust growth model

(good insulation)

Model 3: User variable crust growth model

Model 4: Crust cover is constant down-flow

Crust growth model $(1,2,3$, or 4$)$

Offset for model 3

Slope for model 3

Non-varying crust cover for model 4

BASAL CRUST

Fraction of flow thickness composed of basal crust

Temperature at base $\left({ }^{\circ} \mathrm{C}\right)$

\section{CRYSTALLINITY PARAMETERS}

Latent Heat of Crystallization $\left(\mathrm{J} \mathrm{Kg}^{-1}\right)$

Inverse maximum solids

CRYSTAL GROWTH MODEL OPTIONS

Model 1: Linear crystallization with cooling

Model 2: MELTS-based crystallization

Crystal growth model

$\begin{array}{ll}9.8 & \begin{array}{l}\text { Mass fraction of phenocrysts } \\ \text { Mass fraction of glass } \\ 1.00 \mathrm{E}-01\end{array} \\ 0.08 & \text { HEAT LOSS PARAMETERS } \\ 0.04 & \begin{array}{l}\text { Lava emissivity } \\ \text { Ambient air temp }\left({ }^{\circ} \mathrm{C}\right)\end{array} \\ & \text { CONVECTIVE HEAT LOSS MODEL OPTIONS } \\ 5.5 & \text { Model 1: Free Convection (Qfree) } \\ 5.5 & \text { Model 2: Forced Convection }(\mathrm{Qforce}) \\ 1 & \text { Model 3: Greater of Qfree and Qforce } \\ 100 & \text { Convective heat loss model } \\ & \text { Wind Speed (m/s) } \\ 1150 & \text { Forced Convection friction coefficient } \\ 980 & \text { HEAT LOSS DUE TO RAIN } \\ 140 & \text { Rainfall rate }\left(\mathrm{m} \mathrm{s}^{-1}\right) \\ & \text { Water density }\left(\mathrm{kg} \mathrm{m}^{-3}\right) \\ & \text { Latent Heat of Vaporization }\left(\mathrm{J} \mathrm{Kg}^{-1}\right)\end{array}$

0.15

0.45

0.95

25

1

5

0.0036

7.93E-08

958

$2.80 \mathrm{E}+06$

\section{ENTRAINMENT}

Entrainment flag (1: include heat loss from entrainments 0 : no)

Fraction of effusion rate that is entrained 550

Crust survival time (s)

ENTRAINMENT TEMPERATURE OPTIONS

Option: Use effective radiation temperature

Option: Use temperature of surface crust

Option: Use the high temperature surface thermal component

Option: User-defined constant

0.9023

$-0.1601$

0.99

Entrainment temperature option

Constant entrainment temperature for option 4

$\left({ }^{\circ} \mathrm{C}\right)$

1

550

\section{LAVA PROPERTIES}

$\begin{array}{lll}0.1 & \text { Lava viscosity (Pa s) } & 1000\end{array}$

$700 \quad$ Vesicularity (fraction) $\quad 0.4$

Dense rock density $\left(\mathrm{kg} \mathrm{m}^{-3}\right) \quad 2760$

Lava specific heat $\left(\mathrm{J} \mathrm{kg}^{-1} \mathrm{~K}^{-1}\right) \quad 1225$

3.50E $+05 \quad$ LAVA THERMAL CONDUCTIVITY OPTION

$1.51 \quad$ Option 1: Calculated following Peck (1978)

Option 2: Constant

Thermal conductivity option

Constant thermal conductivity for option 2 


\section{Appendix C: FLOWGO Flow Models}
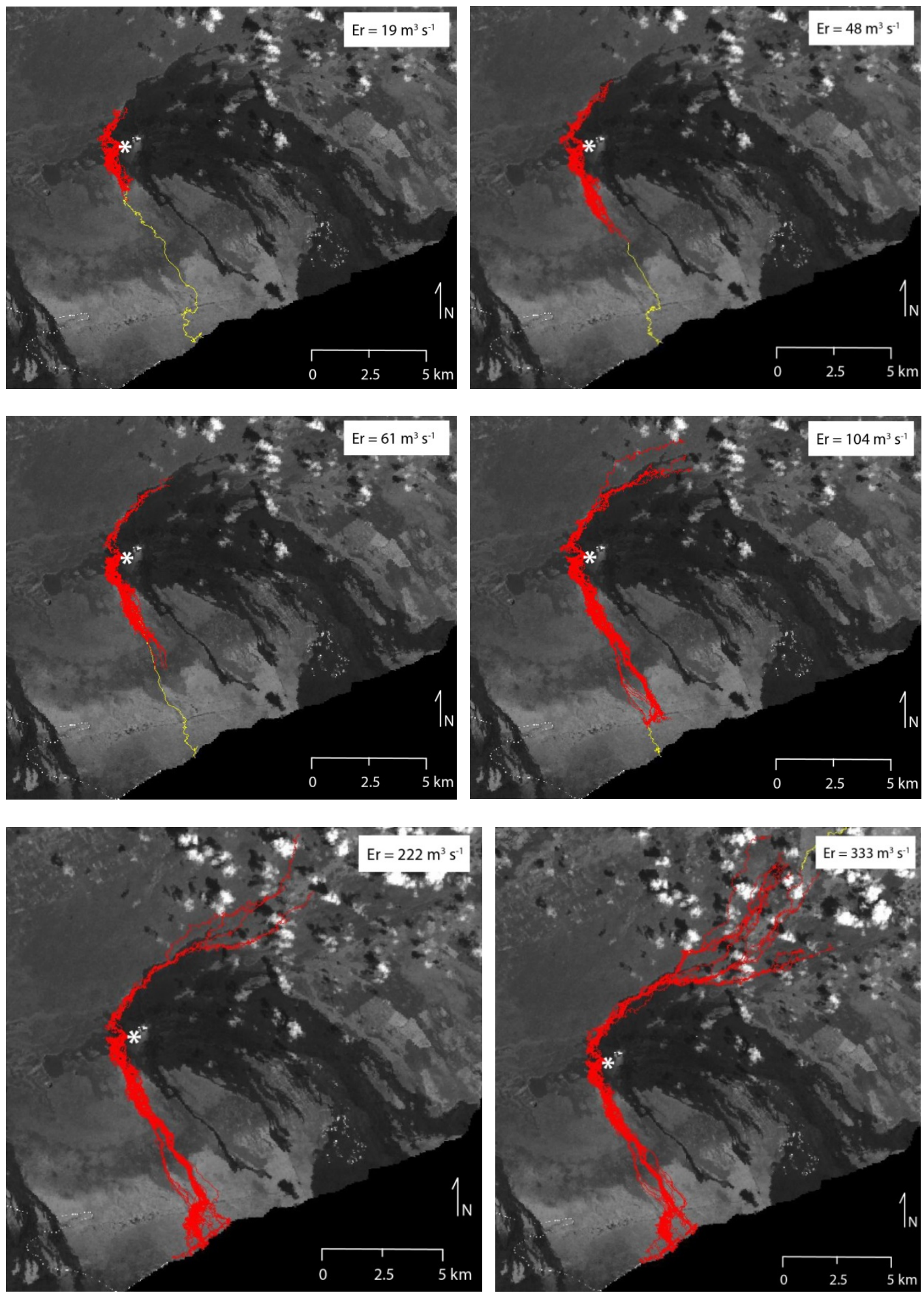

Figure 7.1 FLOWGO models of the August 2011 eruption on the 2000 SRTM DEM. 

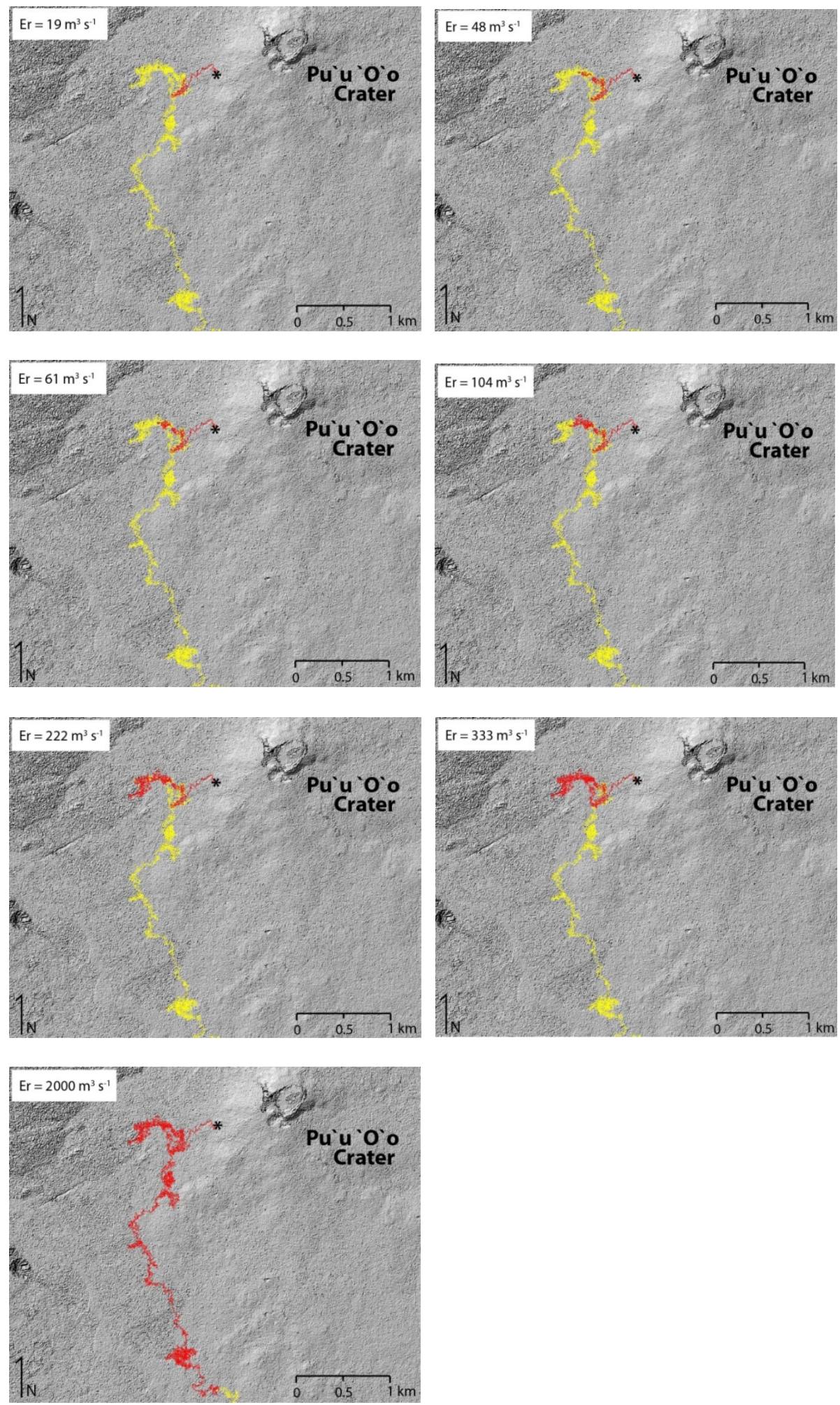

Figure 7.2 FLOWGO models of the August 2011 eruption on the 30 June 2011 TanDEM-X DEM. 


\section{Appendix D: Documentation of Permission to Republish Material}

\section{Copyright permission for Figures 2.2 and 2.3}

Michigan Technological University

1400 Townsend Drive

Houghton, MI 49931

785-760-7195

14 June 2013

Tim Orr

Hawaiian Volcano Observatory

1 Crater Rim Drive

Hawaii National Park, HII 96718

Dear Tim:

This letter will confirm our recent telephone conversation. I am completing a Masters thesis at Michigan Technological University and I would like your permission to reprint excerpts from the following in my thesis:

Orr, T., and M. Patrick (2011), Hawaiian Volcano Observatory Quarterly Report for JulySeptember 2011, USGS internal report.

The excerpts to be reproduced are: a photograph of the August 2011 eruption on the East Rift Zone of Kilauea Volcano, and a GIS map of the same eruption.

The requested permission extends to any future revisions and editions of my thesis, including non-exclusive world rights in all languages, and to the prospective publication of my dissertation by UMI. These rights will in no way restrict republication of the material in any other form by you or by others authorized by you. Your signing of this letter will also confirm that you own [or your company owns] the copyright to the above-described material.

If these arrangements meet with your approval, please sign this letter where indicated below and return it to me in the enclosed return envelope. Thank you very much.

Sincerely,

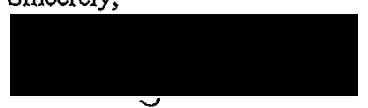

Kelly Wooten

PERMISSION GRANTED FOR THE

USE REOUESTED ABOVE:

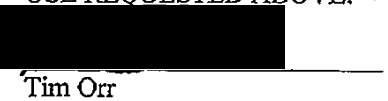

Date: $6 / 14 / 2013$ 


\section{Copyright permission for Figure 3.1}

$6 ! 17113$

Fightslink by Copyright Clearance Center

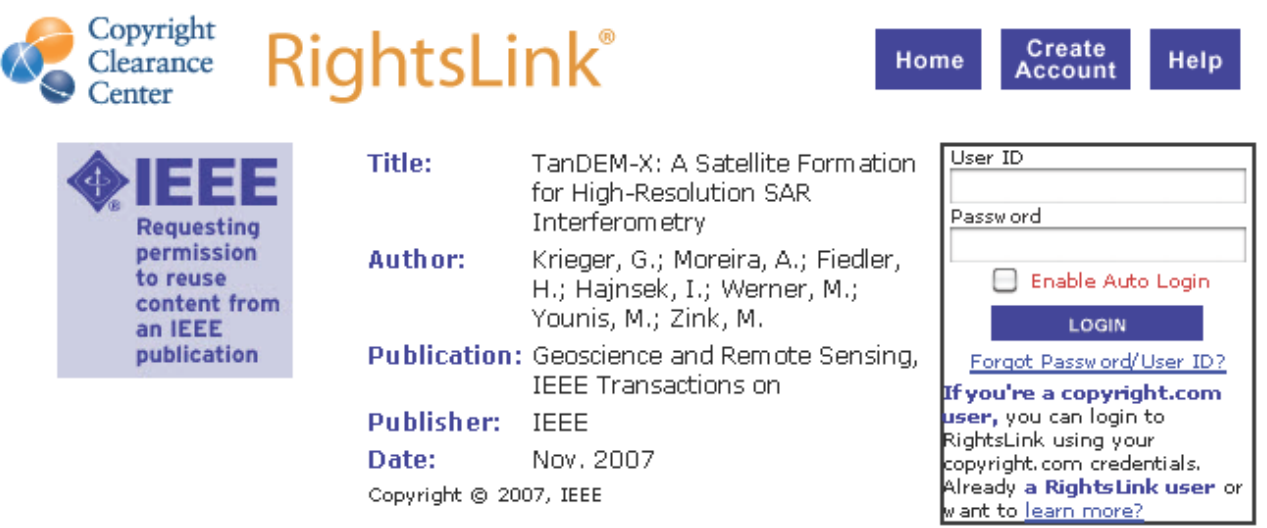

Thesis / Dissertation Reuse

The IEEE does not require individuals working on a thesis to obtain a formal reuse license, however, you may print out this statement to be used as a permission grant:

Requirements to be followed when using any portion (e.g., figure, graph, tabie, or textual material) of an IEEE copyrighted paper in a thesis:

1) In the case of textual material (e.g., using short quotes or referring to the work within these papers) users must give full credit to the original source (author, paper, publication) followed by the IEEE copyright line 2011 IEEE.

2) In the case of illustrations or tabular material, we require that the copyright line 5 [Year of original publication] IEEE appear prominently with each reprinted figure and/or table.

3) If a substantial portion of the original paper is to be used, and if you are not the senior author, also obtain the senior author's approval.

Requirements to be followed when using an entire IEEE copyrighted paper in a thesis:

1) The following IEEE copyright/ credit notice should be placed prominently in the references: 6 [year of original publication] IEEE. Reprinted, with permission, from [author names, paper title, IEEE publication title, and month/year of publication]

2) Only the accepted version of an IEEE copyrighted paper can be used when posting the paper or your thesis on-line.

3) In placing the thesis on the author's university website, please display the following message in a prominent place on the website: In reference to IEEE copyrighted material which is used with permission in this thesis, the IEEE does not endorse any of [university/educational entity's name goes here]'s products or services. Internal or personal use of this material is permitted. If interested in reprinting/republishing IEEE copyrighted material for advertising or promotional purposes or for creating new collective works for resale or redistribution, please go to

http://Www.ieee.org/publications standards/publications/rights/rights link.html to learn how to obtain a License from RightsLink.

If applicable, University Microfilms and/or ProQuest Library, or the Archives of Canada may supply single copies of the dissertation.

\section{BACK}

CLOSE WINDOW

Copyright @ 2013 Copyright Clearance Center, Inc, All Rights Reserved. Privacy statement. 
Copyright permission for Figure 3.10

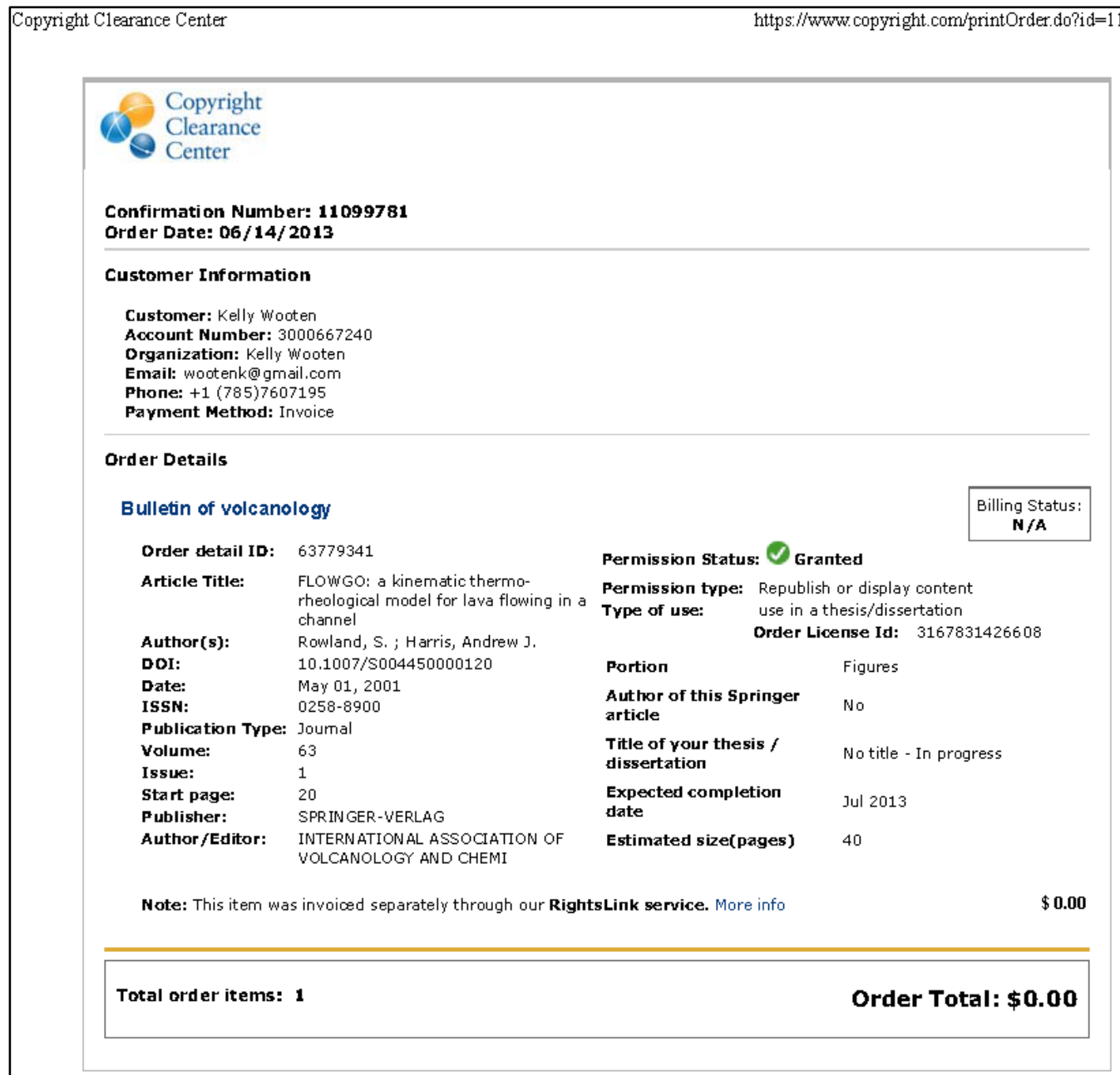

Get Permission | License Your Content | Products And Solutions | Partners | Education | About Us Privacy Policy | Terms \& Conditions

Copyright 2013 Copyright de arance Center 